Rachel L. Pleuthner ${ }^{1 *}$, C. Tracy Shaw ${ }^{2}$,Megan J.Schatz ${ }^{3}$, Evelyn J. Lessard ${ }^{3}$ and H. RodgerHarvey ${ }^{1}$ 23529, USA

${ }^{2}$ Department of Biological Sciences, University of Rhode Island, Kingston, RI 02881, USA

${ }^{3}$ School of Oceanography, University of Washington, Seattle, WA 98195, USA

*corresponding author:rpleuthn@odu.edu

\title{
Lipid Markers of Diet History and their Retention during Experimental Starvation in the Bering Sea Euphausiid Thysanoessa raschii
}

${ }^{1}$ Department of Ocean, Earth, and Atmospheric Sciences, Old Dominion University,Norfolk, VA 
35 Two extended pulsed feeding experiments, following the spring bloom period,investigated lipid retention in the prominent Bering Sea euphausiid (krill)Thysanoessa raschii. These experiments

37 occurredduring late spring and early summer of 2010.Concurrent taxonomic analysis of the natural algal community allowed prey type to be linked tolipid composition of the natural communities.In late spring, experimentalperiods of feeding followed by starvationshowed an overall decrease in total lipid forT. raschii. In early summer, no consistent trend was observed

41 for total lipid with the visible presence ofstorage lipid in some animals.Polar lipids, as

42 phospholipids, were the dominant krill lipid classin both experimentsconstituting $\geq 88 \%$ of total

43 lipid, and triacylglycerols reached a maximum of 5\% of total lipid.The sterols cholesterol and

44 brassicasterol+desmosterol comprised 98-99\% of total sterol abundances in T. raschii throughout

45 both experiments, even after feeding periods when alternativesterols(i.e.the algal sterol 24-

46 methylenecholesterol) accounted for up to 39\% of sterols in potential food particles.Cholesterol

47 abundance andconcentrationincreased during both incubations, likely due to the metabolism of

48 dietary sterols. Major fatty acids observed in krill included C14:0n, C16:0n, C16:1(n-7),

49 C18:1(n-7), C18:1(n-9), C20:5(n-3), and C22:6(n-3) with the diatom-attributed C16:1(n-7)

50 decreasing in abundance and concentration during starvation. Low concentrations of the

51 dinoflagellate-derivedsterol and a novel C28:8 PUFA, typically found in dinoflagellates and

52 prymnesiophytes, indicated predation on protozooplankton in early summer when diatom

53 abundances were low.Thestability of lipid distributions over periods of starvation and

54 intermittent feeding suggest that fatty acidand sterol biomarkers present in this polar euphausiid

55 principally reflectlong-term diet history rather than short-term feeding episodes. 


\section{1. INTRODUCTION}

58 Thysanoessaraschiiare the most prominent euphausiid (also called krill) in the Bering Sea.Neritic

59 and omnivorous, they typically reside in shallower and less saline waters (32.0-32.4)as compared

60 to the other major regional krill, e.g. Thysanoessa inermis, and are widely distributed along the

61 Bering Sea shelf (Pinchuk and Coyle, 2008; Bi et al., 2015). As such, T. raschiiplay a key role in

62 the sub-Arctic food web, particularly as prey for juvenile pollock, marine seabirds, and other

63 higher trophic organisms (Smith, 1991; Adams et al., 2007). Understanding how these krill

64 adapt to seasonal changes in food concentrations in the Bering Sea,and how they utilize stored

65 energy, can provide important insights intoits quality as a food source for these predators and

66 overwintering capabilities.

67 It is generally recognized that $T$. raschii progressively accumulate lipid from early spring

68 through late autumn (Falk-Petersen et al., 1981); however, little information is available that

69 addressesthe longer-term changes in lipid concentration and distribution inT. raschiiin response

70 to a varied food supply.Specific lipidbiomarkershave the potential to track dietary history

71 through periods of feeding and starvation, but temporal information on their retention

72 iscritical.While few specific sterols or fatty acids can be solely linked to one algal group,

73 multiple markers presentamong different algal groups can be used to discern feeding history (e.g.

74 Volkman, 1986). Here we report the results of two T. raschii experimental incubations ofshort-

75 term (i.e. pulsed) feeding followed by starvation using natural communities present in late spring

76 and early summer. These incubations examined (1) the effects of starvation onT. raschiitotal

77 lipid and lipid class composition over time and (2) the relative change among individual sterol

78 and fatty acid biomarkers present in krill diets after a pulse of food from a

79 naturalalgalcommunity.The overall goals were to link lipid biomarker distributions in krill to 
80 their natural diet andto determine how these distributions change during periods of starvation. To

81 our knowledge, this is the first incubation experiment to examine lipid response in sub-Arctic

82 krillusing natural phytoplankton and protozooplankton communities followed by extended

83 starvation under near natural conditions.

84

\section{2. EXPERIMENTAL}

$86 \quad 2.1$ Sampling and Experimental Design

87 Two T. raschiipulsed-feeding starvation and experiments were conducted in late spring (LSp)

88 and early summer (ESu), 2010,using krill from two sites on the Bering Sea Shelf (Figure 1;

89 Table 1) during two consecutive research cruises as part of the Bering Sea Project (see Harvey

90 and Sigler, 2013).Krill were collected using a 60cm Bongo net with black $333 \mu \mathrm{m}$ mesh and solid

91 cod ends,towed obliquely at night to catch animals in good condition during active periods of

92 feeding.Seawater was collected from rosette-mounted Niskin bottles at the krill collection station

93 and one additional station during each cruise for the food pulse in each experiment (four stations,

94 in total). Both T. raschiiexperiments adhered to a similar design(Fig. 2).Healthy, actively

95 swimming individual $T$. raschii with no visible damage were gently placed in filtered sea water

96 (FSW) immediately after collection.Krill weretransferred into a 10L carboy filled

97 withFSW,placed in a temperature-controlled incubator $\left(5^{\circ} \mathrm{C}\right)$, and allowed to clear their guts for

9824 hours. After 24 hours, the krill first subset $\left(\mathrm{T}_{0}\right)$ wasremoved by pouring water from the

99 carboy until the ten krill were obtained, and they were frozen at $-80^{\circ} \mathrm{C}$; theremaining $T$.

100 raschiiwere starved for an additional five to six days.A second subset of six or eight krill

101 werethen frozen; the remaining animals were transferred intoa carboy containing

102 unfilteredBering Sea water collected at the chlorophyll maximum from the food pulse 
stationsand allowed to feed.Followingathree-day feeding period,a third subset of three krill wasfrozen,and the remaining animalswere transferred into a carboy containing fresh FSW.This group of animalswasmaintained in FSW and subsampled three more times (three or four more krill per time point) during the subsequent three week (late spring experiment) or two week (early summerexperiment) starvation incubations.A total of six subsets of animals were collected and sacrificed over the course of each incubation.This amounted to 30 and 32 animals analyzed for the late spring and early summer, respectively. Each time point is referred to by the experiment’s abbreviation (either LSp or ESu) followed by a hyphen and the time point (e.g.LSp- $\mathrm{T}_{0}$ ).At each time point, total length (TL) was measured for individual krill, observations on life stage and reproductive statewere recorded, and animals composited and frozen at $-80^{\circ} \mathrm{C}$.It is possible that a small percentage of the animal's original wet weight was lost during the freezing process due to water exclusion. For information regarding krill sub-samples from each experiment, refer to Appendix 1. Seawaterwas collected ator near the chlorophyll max for all four stations using Niskin bottles; it was subsampled for chlorophyll, algal cell enumeration and identification, lipid analysis, andparticulate organic carbon and particulate nitrogen (POC/PN) measurements.Seawater subsampled for lipids, hereafter referred to as water column particles, was filtered onto pre-combusted $47 \mathrm{~mm} \mathrm{GF} / \mathrm{F}$ filters and stored at $-80^{\circ} \mathrm{C}$ until processing at the lab. Any visible zooplankton were removed from the filter prior to freezing. For the late spring experiment, the krilland seawaterwere collected at station 111, and the seawater for the food pulse collected from station 168; the water column particle samplescollected from these locations will hereafter be referred to as LSp-I (late spring, initial) and LSp-P (late spring, food pulse). Similarly, for the early summer experiment,T. raschiiand plankton were collected fromstation 19 
125 and fed with communities from station 46; the water column samples will be referred to as ESu-

126 I(early summer, initial) and ESu-P (early summer, food pulse), respectively (Fig. 1).

$128 \quad 2.2$ Lipid extraction and analyses

129 Composited krill, collected at each experimental time point,were weighed and extracted wet via 130 microwave-assisted solvent extraction (MASE; MARS-5 system) with 2:1

131 dichloromethane:methanol (DCM:MeOH) (see Harvey et al., 2012 and references

132 therein).Resulting total lipid extract (TLE) was filtered through combusted, solvent-rinsed glass

133 wool to remove particulates; evaporated to dryness; and redissolved in the original 2:1

134 DCM:MeOH solvent mixture. For krill samples, the TLE was split to accommodate total lipid 135 andlipid class analysis,as well ashydrolysis for individual markers.Base hydrolysis of total lipid 136 used $0.1 \mathrm{~N} \mathrm{KOH}$ with $5 \alpha$-cholestane and C19:0n fatty acid serving as the internal standards for 137 the neutral and polar fractions, respectively. Water column particles, which include both living 138 (algal) and non-living detritus, were similarly extracted. The entirety of the particle extract was 139 hydrolyzed and used to measure individual markers.

140 Analysis of total lipid and lipid classes followed methods of Harvey et al. (2012), with an

141 Iatroscan MK-V TLC-FID instrument with Agilent (ChemStation) integration and quantification.

142 Lipid standards (Sigma Aldrich, Co.)- including dipalmitoylphosphatidylcholine (for polar 143 lipids; PL), cholesterol (for sterols; ST), C19:0n fatty acid (for free fatty acids; FFA), glyceryl 144 trioleate (for triacylglycerols; TAG), and palmityl stearate (for wax esters; WE) - were run in 145 parallel and used to generate response curves to determine concentration.

146 Following base hydrolysis of total lipid, neutral lipidswere partitioned with 9:1 hexane :

147 diethylether. Following acidification with concentrated hydrochloric acid (aq), polar fatty acids 
148 were similarly partitioned. Neutral components were derivatized using BSTFA to form their

149 trimethylsilyl (TMS) products, and fatty acids were converted into their corresponding methyl

150 esters using boron trifluoride (10\% in methanol).Both fractions were quantified with an Agilent

151 6890N gas chromatograph withflame ionization detector (GC-FID) and identified with an

152 Agilent 6890 gas chromatograph coupled to an Agilent5973N mass spectrometer (GC-MS).Both

153 instruments utilized a 60m DB5-MS column. Chromatographic details are described in detail in

154 Belicka et al. (2002), with an inlet temperature of $250^{\circ} \mathrm{C}$. Neutral lipids were analyzed in detail;

155 however, for brevity, most individual components werecategorized and summedas total alcohols,

156 sterols, tocopherols, wax esters, or glycerol monoethers.For identification of double bond

157 positionsof fatty acids in krill, a portion of fatty acids were converted topicolinyl esters

158 (Destaillats and Angers,2002) to provide confirmatory fragmentation information.

159 Polyunsaturated fatty acids and fatty acids in low concentration werealso validated by

160 comparison of retention time and mass spectra of a 52-component fatty acid methyl ester

161 standard (Nu-Chek Prep, Inc.).

162

$163 \quad 2.3$ Particulate organic carbon and particulate nitrogen

164 Water column samples for POC/PN were filtered through pre-combusted 25mm GF/F filters and

165 frozen at $-80^{\circ} \mathrm{C}$. Filters were thawed, acidified drop-wise with $\mathrm{HCl}(\mathrm{aq})$ for an hour in a clean

166 desiccator, and transferred to a $60^{\circ} \mathrm{C}$ oven to dry. Samples were repackaged in combusted foil

167 packets foranalysis by standard methods (Harvey et al., 2012).

168

$169 \quad 2.4$ Autotrophic and heterotrophic plankton abundance and biomass 
170 The community taxonomy, size, and trophic composition of microplankton assemblages present

171 where the krill were isolated and in food pulse additionswere analyzed to determine the effect of

172 prey type and quantity on the chemical composition of T. raschii. Results here, as well as results

173 from other grazing experiments, suggest that $T$. raschii do not consume prey $<5 \mu \mathrm{m}$ in size

174 (Agersted et al. 2010; Lessard, unpublished data). Picoplankton (eukaryotes and cyanobacteria)

175 and some portion of the nanoflagellates (those $<5 \mu \mathrm{m}$ ) are probably not part of the prey field

176 available to krill; nevertheless, they do contribute to the particulate lipid pool and have been

177 included here for completeness.

178 Samples for autotrophic and heterotrophic plankton identification, enumeration and sizing were

179 collected with Niskin bottles and preserved with either acid Lugol's (5\% final concentration) or

180 with glutaraldehyde (0.5\% final concentration). Glutaraldehye fixed samples were stained with

181 DAPI and proflavine, and then filtered onto $0.8 \mu \mathrm{m}$ or $0.2 \mu \mathrm{m}$ black polycarbonate membrane

182 filters (Lessard and Murrell, 1996). Slides were stored frozen until analysis onshore.

183 Live samples were obtained at station LSp-I and analyzed with a benchtop FlowCAM (Fluid

184 Imaging Technologies, Yarmouth, ME) running IMS software to image live plankton samples

185 for semi-quantitative assessments of the $>5 \mu \mathrm{m}$ plankton community.Samples were gently

186 drawn through $1.4 \mathrm{~mm}$ silicone tubing and a $2 \mathrm{~mm} \times 0.1 \mathrm{~mm}$ flow cell with a peristaltic pump at a

187 flow rate of $1 \mathrm{ml} / \mathrm{min}$ for $10 \mathrm{~min}$. Images were collected in the fluorescence/scatter trigger mode 188 using a 10x objective.

189

$190 \quad$ 2.4.1 Microscope Counts

191 Known volumes of Lugol's preserved samples were settled in counting chambers and examined 192 with a Zeiss inverted microscope at 400x magnification for diatoms, ciliates and dinoflagellates 
$193>40 \mu \mathrm{m}$. Glutaraldehyde preserved samples were examined with a Zeiss standard epifluorescence

194 microscope. Slides with $0.8 \mu \mathrm{m}$ filters were observed at 500x magnification for all other

195 dinoflagellates and flagellates $>10 \mu \mathrm{m}$. Slides with $0.2 \mu \mathrm{m}$ filters were examined at $1250 \mathrm{x}$

196 magnification for cyanobacteria, picoeukaryotes and nanoflagellates. Autotrophs and

197 heterotrophs were differentiated based on chlorophyll fluorescence.

198

$199 \quad$ 2.4.2 Biomass Estimation

200 Picoplankton (cyanobacteria and picoeukaryotes) were sized using images taken with a

201 QImaging Retiga EX charged couple device (CCD) camera and Image Pro Plus software.

202 Measurements of all other cells were determined using a computer aided digitizing system (Roff

203 and Hopcroft, 1986). Cell volumes were calculated using geometric equations. Carbon was

204 calculated using the carbon to volume equations of Menden-Deuer and Lessard (2000) for

205 diatoms, dinoflagellates and nanoplankton;the equations ofWorden et al. (2004) were similarly

206 used to calculate carbon for picoplankton.

207

$208 \quad 2.5$ Statistical Analyses

209 Non-parametric tests were used to compare T. raschii biomarkers to those of their food using

210 Primer v5 software. A series of group cluster and multi-dimensional scaling (MDS) analyses

211 were run using Bray-Curtis dissimilarity.Cluster analysis results were incorporated into the MDS

212 plots to show groupings at the $30 \%$ dissimilarity level for sterols and fatty acids or the $20 \%$

213 dissimilarity level for total lipids. To compare the late spring and early summer krill, the wet

214 weight concentrations of lipid classes were analyzed after a square root transformation. For

215 sterols and fatty acids, each analysis utilized the relative abundance of markers to directly 
216 compare water column particles to krill subsamples with no transformation. Due to the

217 differingmetabolic functions of sterols and fatty acids, the two categories of biomarkers were

218 analyzed separately.Similarity percentage analysis (SIMPER) was used to determine the neutral

219 and polar lipid components that differentiatedkrill from the water column samples in the data sets

220 (70\% cut-off).This cutoff was chosen because it included a majority of the overall abundance

221 without including a large number of fatty acids that made little contribution to the overall

222 total.Fatty acids and sterols were,again, analyzed separately.

223

224 3. RESULTS

2253.1 Autotrophic and Heterotrophic Microplankton Community Structure

226 The abundance and estimated carbon biomass in each of five autotrophic categories (diatoms,

227 dinoflagellates, nanoflagellates, picoeukaryotes and cyanobacteria) and three heterotrophic

228 protist categories (dinoflagellates, ciliates and nanoflagellates)were counted and calculated for

229 stations LSp-P, ESu-I, and ESu-P(Table 2).Despite the relatively short time difference of several

230 weeks, the two experimental incubationsbeganunderdiffering conditions. Ice had recently

231 retreated at the late spring LSp-I station, the water was cold $\left(-0.9^{\circ} \mathrm{C}\right)$, and the phytoplankton

232 community was characterized byice-associated diatoms. Byearly summer, at ESu-I, the

233 southeastern shelf system had transitioned to summer conditions and was dominated by small,

234 non-diatom autotrophs and heterotrophic protists.

235

236 Late SpringInitial \& Food Pulse Microplankton

237 FlowCAM data showed that the surface algae at station LSp-I, where krill for the late spring

238 experiment were collected, was dominated by ice-associated chain forming pennate diatoms 
239 (Fragillariopsissp.) and the centric diatom, Thalassiosira sp.;Pseudo-nitzschia sp., Chaetoceros

240 sp., and Entomoneis sp.,were also present. Autotrophic and heterotrophic dinoflagellates and

241 ciliates were rare.

242 At the food pulse station LSp-P, pelagic centric diatoms dominated the autotrophic biomass

243 (Table 2).Chaetocerossocialis,the most abundant and largest phytoplankton biomass component

244 (38\% of total autotrophic biomass), was followed bythe larger, but less numerousThalassiosira

245 sp. (26\% of autotrophic biomass). Cyanobacteria were absent, but picoeukaryotes were present

246 in low abundances. At this stage in the spring bloom, the heterotrophic protist grazers were

247 relatively low in abundance and biomass (21\% of the total carbon biomass); dinoflagellates and

248 ciliates dominated the heterotrophic biomass (Table 2).

250 Early Summer Initial and Food Pulse Microplankton Composition

251 At station ESu-I, where the early summerexperimental krill were

252 collected,heterotrophicnanoflagellates dominated the plankton biomass. Heterotrophic and

253 autotrophic nanoflagellate abundanceswere similar, but the heterotrophic nanoflagellates

254 contributed the most biomass (49.5\% of the total) due to their larger average size.The autotrophic

255 flagellates included cryptophytes and the prymnesiophyte, Phaeocystispouchetii. This station

256 also had the lowest diatom abundance and biomass of the sampled stations, but the greatest

257 abundance of heterotrophs of all stations (63\% of the total). Picoeukaryotes and cyanobacteria

258 were present in low numbers and contributed very little to total biomass.

259 The early summerfood pulse station ESu-Pwas located in a diatom bloom dominated by

260 Chaeotoceros spp. While other autotrophs were present (picoeukaryotes were in relatively high

261 abundance at $3000 \mathrm{~mL} / \mathrm{L}$ ), the diatoms made up $95 \%$ of the autotrophic biomass, and $60 \%$ of 
262 the total biomass. Heterotrophs only contributed $40 \%$ of the biomass at station ESu-P; however,

263 of the three stations for which quantitative data was available, this station was characterized by

264 the highest heterotrophic biomass (52 $\mu \mathrm{gC} / \mathrm{L})$, comprising large-sized heterotrophic

265 dinoflagellates and ciliates, as well as nanoflagellates.

266

267 3.2Characteristics of the Experimental Krill

268 The range of krill total lengths was similar for both experiments $(17-26 \mathrm{~mm})$, but the late spring 269 experiment tended toward the 18-20mm range (avg. 19.75mm) while the slightly largerearly 270 summer animals(avg. $22.71 \mathrm{~mm}$ ) were generally in the 21-23 mmrange (Appendix 1). All krill

271 in both incubations were adults. In the late spring experiment, 53\% of the krill showed evidence

272 of reproductive activity, with developing ovaries and spermatophores in the females and

273 developed sperm glands in the males. None of the females used for lipid analysis were carrying

274 broods of mature eggs. Average total length of krill increased slightly between the initial

275 collection and first subsample, but decreased slightly (an average of $0.09 \mathrm{~mm} / \mathrm{d}$ ) at each

276 subsequent time point. In the early summer experiment there was no evidence of reproductive

277 activity, but $28 \%$ of the animals had visible accumulation of clear lipids under the carapace,

278 including the animals removed after the feeding pulse and all animals from the last two

279 subsamples. Average total length increased between the initial collection and first subsample, 280 decreased for the next two subsamples (an average of $0.3 \mathrm{~mm} / \mathrm{d}$ ), then increased for the last two 281 subsamples (an average of $0.16 \mathrm{~mm} / \mathrm{d}$ ).

282

$283 \quad$ 3.3The lipid response by Thysanoessa raschii 
284 Total lipid concentrations(mg lipid/g wet weight) in bulk krill composites showed different

285 patterns between late spring and summer feeding and starvation regimes (Fig 3A). Late spring

286 krill showed a58\% decrease in total lipid concentration between the beginning and end of the 31-

287 day experiment.Early summer krill did not show any consistent increases or decreases in total

288 lipid during the experimentregardless of the lipid metric.Both late spring and early summer krill

289 showed an increase in lipidstores after the three-day feeding period, as compared to the previous

290 time point with a much larger increase seen in theearly summerincubations. After the $\mathrm{T}_{2}$ time

291 point, individuals in both experiments showed an overall decrease in total lipid at the final $\left(\mathrm{T}_{\mathrm{f}}\right)$

292 time points.

293 The abundance of the fivemajor lipid classesinT. raschiivaried little betweenexperiments (Fig

294 3B).Phospholipids (PL)remainedthe dominant classthroughout,accounting for 90-94\% of $T$.

295 raschiilipids overthe late spring and 89-96\%ofearly summer incubations. The greatestincrease in

296 PLabundance occurred in early summer animals after the 3-day grazing period. In contrast, no

297 differencesin lipid class abundance were seen for late springanimals fed under nearly identical

298 conditions. Triacylglycerol (TAG), often considered to be the major storage lipid in T. raschii,

299 was in low abundance relative to polar lipid, but was higher in larger,early summeranimals than

300 in thesmaller,late spring krill(1.7-4.9\% and 1.1-1.9\%, respectively).Average free fatty acidswere

301 low (4.9\%), but often greater than average TAG abundances (2.3\%) inlate spring krill. Wax

302 esters, a minor storage lipid for T. raschii, averaged 1.1\%(late spring) and 1.5\%(early summer).

303 Sterol abundances varied little between experiments (0.65 and $0.71 \%$ ), whichlikely reflects their

304 largely structural role in krill membranes.

305

$306 \quad$ 3.4Neutral Lipid Composition 
Total neutral lipid concentrations, and relative abundances as a percent of total neutral lipids, were calculated for alcohols, sterols, tocopherols, waxes, and glycerol monoethers for all samples over both experimental incubations (Table 3). The dominant alcohol among all samples was phytol (92-97\% of all alcohols), which increased in relative abundance in krill after feeding in both experiments (Table 3). Other alcohols that contributed at least $1 \%$ of the total alcohol content in samples included C20:1 (0.5-2.5\%) and C22:1 (0.8-3\%), which displayed no discernible trend over time. Glycerol monoethers (GME), or monoalkyl glycerol ethers, were in low abundance in both animal and particle compartments (Table 3).Two tocopherols were observed in krill at all experimental time points: $\alpha$-tocopherol (vitamin E) and a tocomonoenol called marine-derived tocopherol (MDT). In both experiments, $\alpha$-tocopherol represented 97-99\% of tocopherols, and MDT comprised another $0.8-2.9 \%$ (late spring) to $0.4-1.2 \%$ (early summer). The only tocopherol observed in water column particles was $\alpha$-tocopherol, which was present in trace quantities ( $<0.1 \%$ neutral lipids).For brevity, all tocopherols have been summed and shown in Table 3.

The relative abundances of sterols in krill and water column particles were measured for the late spring (Table 4) and early summer (Table 5) experiments.Sixsterols comprised $>80 \%$ of particle sample sterols at each of the four stations: 24-norcholesta-5,22-dien-3 $\beta$-ol (24norsterol);cholesta-5,22-dien-3 $\beta$-ol (22-dehydrocholesterol);cholesta-5-en-3 $\beta$-ol (cholesterol);24methylcholesta-5,24(28)-dien-3ß-ol (24-methylenecholesterol);and the coeluting choelsta-5,24-

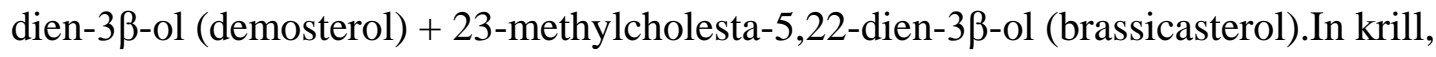
brassicasterol was in low abundance or absent. Of these sterols, SIMPER analysis revealed cholesterol, 24-methylenecholesterol, and the combined desmosterol + brassicasterol were the most prominent contributors to differences among krill and water column particles. 
330 Water column particle samples at both late spring stations LSp-I and LSp-P were dominated by 331 the diatom derived sterols 24-methylenecholesterol (28.1\% and 39\%, respectively), followed by

332 desmosterol + brassicasterol (26.1\% and 17.4\%). Together with cholesterol (10.2\% for LSp-I

333 and 13.8\% for LSp-P) and 24-norsterol (11.8\% and 9.8\%),those four sterols alone were

334 responsible for $76.2 \%$ and $80 \%$ of total sterols (Table 4 ). At the heterotroph-dominated early

335 summer station ESu-I, cholesterol was the primary sterol, followed by

336 brassicasterol+desmosterol (Table 5). Cholesta-5,22-dien-3 $\beta$-ol and 24-norsterol each

337 contributed over $10 \%$ of the total sterols. The primary sterols found in ESu-P were the same as

338 the two late spring stations; cholesterol abundance was approximately 2x higher than at LSp-I

339 and LSp-P, and the combined brassicasterol + desmosterol about 2x lower in abundance.

340 For all T. raschii subsamples, cholesterol and the combined brassicasterol+desmosterol were the

341 most abundant sterols throughout thelate spring experiment, comprising 98-99\% of all sterols

342 (Tables 4 and 5).Dietary phytosterols decreased in abundance during starvation, with an increase

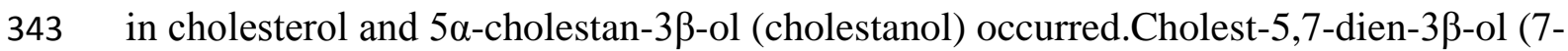

344 dehydrocholesterol), also increased in abundance over time. 345

$346 \quad$ 3.5Fatty Acids

347 Among the large suite of observed fatty acids, major groups defined as saturated fatty acids 348 (SFA), monounsaturates (MUFA) and polyunsaturates (PUFA) varied in particle samples 349 reflecting the composition of the plankton community present at each station (Fig 4; Appendices 3502 and 3).In contrast, fatty acid abundance and distribution in T. raschiiremained relatively stable 351 throughout both starvation experiments(Fig 4). Relative percentages of SFA, MUFA, and PUFA 352 (as \% SFA / \%MUFA / \% PUFA) for late spring krill averaged 30.6 / 39.6 / 29.8 over the 
353 entirety of the experiment (31 / 41 / 28 at the beginning; 33 / 36 / 31 at the end). Average

354 abundances shifted only slightly in early summer krill with relative abundances of SFAs

355 increasing and PUFAs decreasing (37.3/ 38.3/ 24.4), with starting ratios of 37/ 39/24and ending

356 at 37 / 38 / 25. In particlesamples, station LSp-I, the ice diatom station, ratios were 28.5/ 24.7 /

357 46.8, reflecting the high abundance of PUFAs, specifically C20:5(n-3) and C22:6(n-3). The two

358 stations with high Chaetoceros abundances, LSp-P and ESu-P had ratios of 32.1/ 43.4/ 24.5

359 and42.5/45.7/ 11.8, respectively. The heterotroph-dominated station LSu-Icame in at 29 / 49 /

36022.

361 A suite of seven fatty acids comprised the majority of total fatty acids in all krill and most

362 particle samples: C14:0n, C16:0n, C16:1(n-7), C18:1(n-7), C18:1(n-9), C20:5(n-3), and C22:6(n-

363 3) (Fig.4). These fatty acids comprised $91.3 \%$ of the total fatty acids at the beginning of the late

364 spring experiment, decreasing to $88.4 \%$ at the end of the experimental period.A similar trend was

365 seen in summer (87.9\% at the start of the early summer incubationand $86.1 \%$ at the conclusion).

366 SIMPER analyses revealed that these seven fatty acids were responsible for the dissimilarity

367 between krill and particle samples.The heterotroph-dominated station ESu-I, maintained the

368 highest relative abundances of C14:0n and C16:1(n-7) fatty acids of the four particle samples at

$36910 \%$ and 44\%. Interestingly, the abundances of C20:5(n-3) and C22:6(n-3) at ESu-I were similar

370 tothose at diatom-dominated station LSp-P (10\% and $2 \%$ versus $10 \%$ and $3 \%$,

371 respectively).Chaetoceros fatty acids (C14:0, C16:0, and C16:1(n-7)) become more prominent at

372 the late June food pulse, station ESu-P, and Chaetoceros also account for even more of the

373 estimated carbon than they did at station LSp-P (Table 2). The highest C20:5(n-3) and C22:6(n-

374 3) PUFA abundances at $14.3 \%$ and $12.8 \%$, respectively, occurred at the ice diatom station LSp-I. 
375 By comparison, the next highest abundances for those PUFAs occurred at LSp-P with 10.4\% and $3763 \%$, respectively.

377 While the relative abundances of most individual fatty acids did not change more than3\%

378 between the initial and final time points foreither T. raschiiexperimental incubation, the C16:1(n-

379 7) fatty acid decreased over 8\%between the beginning and end of the late spring experiment. The 380 two SFAs (C14:0n and C16:0n) and C18:1(n-9) were more abundant in the larger, early summer 381 krill than the smaller,early spring krill averaging 7\%, 26\%, and 11\% versus 5\%, 23\%, and 9\%.

382 The opposite held true for the two main PUFAs, (C20:5(n-3) and C22:6(n-3)), and C16:1(n-7), 383 which averaged 18\%, 7\% and 18\% for the latespring krill and 16\%, 5\%, and 14\% for the early 384 summer animals. The C18:1(n-7) showed little change.

385

386

387 The multidimensional scaling (MDS) plots generated for the krill lipid classes from both 388 389 390 391

\subsection{Statistical Analyses} experiments(Fig 5A) showed a horizontal separation of the late spring and early summer krill, likely driven by the higher concentration of phospholipid in the summer animals. The sterol MDS plot (Fig 5B) showed three separate clusters: all subsampled T. raschii, particle sampleESu-I, and the other three particle samples (LSp-I, LSp-P, and ESu-P). In the fatty acid MDS plot (Fig 5C), there were also three distinct clusters: all subsamples animals, particle sample LSp-I, and the other three particle samples.

\section{DISCUSSION}

The distribution of individual lipid biomarkers in particle samplesaccuratelyreflected theseasonal algal transitionfrom late springwhen ice diatomswere prominentto early summerwhen the 
398 heterotrophic population was steadily increasing.Yet, after three days of grazing on the natural

399 algal community at in situconcentrations, theincreased lipid stores seen in T. raschiiin both

400 incubations did not uniformly reflect their available diets.This suggests that lipid composition in

401 krill reflects the longer-term interaction of diet and metabolism and is not rapidly altered by

402 short-term feeding activities. Instead, lipid biomarkers may be more useful as long-term

403 integrators of diet history.

404 Fundamentaldifferences between T. raschiiin the late spring incubation and theearly summer

405 incubation are apparent in the elevated concentrations of total lipid and increased abundance of

406 TAG storage lipid class in early summer krill, as compared to late spring krill.Early summer krill

407 alsoappeared to maintain tighter metabolic homeostasis with regard to sterols and fatty acids

408 types (SFA, MUFA and PUFA) throughout the entireincubationversus those in the late spring

409 incubation. That is not to say that dietary lipids are not informative; the diatom-derived C16:1(n-

410 7) fatty acid abundance was nearly 9\% higher in spring krill (21.3\%) than in summer krill

411 (12.7\%), reflecting the decreased presence and consumption of diatom food at their catch

412 stations (LSp-I and ESu-I, respectively). The greatest change in sterol abundances came not

413 from an increase in phytosterols themselves, but from cholesterol as a likely metabolic product

$414(+5.7 \%$ in late spring and $+1.7 \%$ in early summer $)$. Both of these changes are also noted in the

415 wet weight concentrations, and are likely a product of the metabolic pathways associated with

416 short-term starvation.The following subsections discuss physical differences between the $T$.

417 raschii in both incubations, relate biomarkers found in krill to their known or suggested origins,

418 and compare these results with other experiments.

$420 \quad$ 4.1 Role of life stage and reproductive status on lipids 
421 Krill physiology can have a confounding effect on studies that span an extended period of time.

422 Prior studies have shown krill to shrink in size during periods of low food availability or intense

423 reproductive activity (Marinovic and Mangel, 1999; Shaw et al., 2010). In the present study,

424 both of these conditions were present during the late spring experiment. Many of the animals

425 among the first three incubation time points showed clear signs of being reproductively active.

426 Despite this, no krill in the last two time points showed signs of being reproductively active. The

427 average length of individuals also declined steadily over the experimental period. It is possible

428 that by the latter part of the experiment the animals were responding to the low food availability

429 by abandoning reproductive activity and reducing their size as a survival strategy. Thus,

430 although the averageanimal totallength for the late spring experiment was smaller than for the

431 early summer experiment, this may have been driven in part by animals shrinking over the

432 course of the incubation. The food pulses for both experiments were dominated by the same

433 prey item - the diatom Chaetoceros-and so, these results may reflect differential responses by

434 the krill in relation to where they were in their seasonal cycle of spawning (late spring) and lipid

435 accumulation (early summer). This is also supported by the visible lipid stores in the carapaces

436 of $T$. raschiiobserved during the first two time points of the early summer experiment.

437 MDS analysis of krill lipid class abundances showed clear separation of the late spring and early

438 summer krill likely due to the enhanced presence of the TAG storage lipids and PL in the early

439 summer krill.

440

$441 \quad$ 4.2 Krill and Particle Biomarkers

442 Several lipid functional forms - sterols, alcohols and waxes, tocopherols and fatty acids - have

443 the potential to provide information regarding the diet history of T. raschii. The chemical 
444 signatures of potential krill planktonic prey items or alternative food sourcesfor krill are linked to 445 prey items.

446 Sterols

447 Sterols in particles reflected the changing algal communities throughout thelate spring 448 experiment.Diatom-associated sterols 24-methylenecholesterol and desmosterol + brassicasterol 449 were the primary sterols present at stations LSp-I and LSp-P, in keeping with the observed 450 phytoplankton distribution. Most notably, 24-methylenecholesterol had a large presence at 451 station LSp-P where Chaetoceros sp. was the dominant diatom. Cholesterol and 24452 methylenecholesterol are the dominant sterols in some species of Chaetoceros (Volkman, 1986 453 and references therein;Tsitsa-Tzardis et al., 1993). Cholesterol was the third most abundant 454 sterol after the coeluting brassicasterol+desmosterol. Also prevalent were 24-norsterol, 455 commonly attributed to dinoflagellates (Ghosh et al., 1998; Thompson et al., 2004), and 22456 dehydrocholesterol, found in significant quantities in diatoms, and to a lesser degree, in 457 numerous other phytoplankton groups (Volkman, 1986; Barrett et al., 1995).

458 It has been proposed that other crustaceans can convert desmosterol and 24-methylenecholesterol 459 to cholesterol through dealkylation. The most notable change in animal sterols took place during 460 the late spring starvation period: between day 0 and day 6,cholesterol increased in abundance 461 from $90.5 \%$ to $94 \%$, and brassicasterol+desmosterol decreased from $7.5 \%$ to $4.4 \%$. Interestingly, 462 no relative increases in dietary sterols were observed in the krill after completion of the three-day 463 grazing period. If this metabolic pathway also applies to T. raschii,itwould explain the gradual 464 decrease in relative abundance of those two dietary sterols and the overall increase in cholesterol 465 in krill during starvation periods in both experiments(Kanazawa, 2001 and references therein). 
466 Some algal sterols, though significant contributors to the total available sterols in algal diets,

467 cannot be directly linked to consumption by grazers due to limited assimilation during digestion.

468 For example, the $4 \alpha$ sterols arecommonly attributed to dinoflagellates and much less so to

469 diatoms (Dahl et al., 2004 and references therein; Rampen et al., 2010), but are not absorbed

470 bygrazing calanoid copepods (Harvey et al., 1987) and likely other crustaceans. This constrains

471 the tracking of specific consumption for some algal groups. In the present study, while

472 dinoflagellates were observed as part of the phytoplankton community, no $4 \alpha$ sterolswere

473 observed in any of the krill in either experiment.

474 Cholesterol, which assists in maintaining membrane fluidity, is the most abundant sterol in all $T$.

475 raschii subsamples. In order to obtain cholesterol, krill must either consume it directly or modify

476 suitable dietary sterols. Cholesterol is found in prey items like dinoflagellates and diatoms, and

477 may constitute $50 \%$ or more of total sterols insome of these microplankton species(Volkman,

478 1986); however, its high concentrations in krill make it difficult to separate the dietary

479 cholesterol contribution from the pre-existing krill cholesterol.

480 Other sterols may be more useful indicators of which plankton group was consumed. For

481 example, cholest-5,7,22-trien-3 $\beta$-ol, present at the heterotrophic station ESu-I in abundance of

$482<0.1 \%$ and present in all summer krill, holds the potential to be a marker for predation on

483 heterotrophic protists in a marine environment. No autotrophic organisms have been found to

484 contain this sterol, to date, but it has been detectedin some strains of yeast, some ciliates, and

485 other heterotrophic protists, such as the heterotrophic dinoflagellate Lessardia elongata (Engel et

486 al., unpublished data). In feeding experiments, this triene was not detected in prey items of $L$.

487 elongata, but was seen in the predator, suggesting that it is not a dietary constituent, but a

488 product of biotransformation within the heterotrophic dinoflagellate itself. Another potentially 
useful sterol marker is 24-methylenecholesterol, which was highly abundant in the water column particles when diatoms, either ice-associated or pelagic, dominated the system. Its abundance in krill decreased throughout the starvation period in both experiments.

The three clusters revealed by the MDS plot of sterol relative abundance for all samples can likely be explained largely by cholesterol and 24-methylenecholesterol (Fig 4B).Separation ofkrill subsamplesfrom the particle samples, and their tight clustering, may be attributed to the high abundance of cholesterol and the lack of a number of sterols found in the natural community samples. The particle samples from stations LSp-I, LSp-P, andESu-P all contained large concentrations of diatoms, particularly Chaetoceros, and correspondingly 24methylenecholesterol comprised $17-26 \%$ of their total sterols.

Throughout the course of the starvation experiments, most sterols,with cholesterol being a primary exception, decreased in abundance, but did not disappear completely. If sterols are being used as a proxy for grazing on particular taxa and the signatures do not change rapidly over time as seen here, then the sterols can be more reflective of long-term dietary history. Therefore, it is likely more effective to utilize chemical markers to focus on seasonal and spatial changes in phytoplankton composition and diet.

\section{Other neutral lipids}

A number of other neutral lipids observedmight serve as tracers for dietary history once the time frame for metabolim is established.Wax esters are a minor storage lipid for T. raschii (Sargent and Falk-Petersen, 1981). Small amounts of phytol-derived wax esters were seen in T. raschii, generally with C14:0 or C16:0 fatty acids comprising the acyl portion of the chain, as determined by mass spectra. Phytol-derived waxes have been documented in a variety of sources ranging 
512 from marine bacteria and dinoflagellates to sediment (Withers and Nevenzel, 1977; Rontani et

513 al., 1999). Determining which wax ester moieties are produced by T. raschii versus consumed

514 could provide options for tracking diet history.

515 The marine-derived tocopherol (MDT) was present in very low concentrations in krill, but absent 516 in particle samples. This tocomonoenol, found in cold-water organisms, has been documented at 517 up to 8\% of total tocopherols in the Antarctic E. superba (Dunlap et al., 2002), which is much 518 higher than the abundance found here (1-3\% of tocopherols in late spring and $0.4-1.2 \%$ in early 519 summer). Its origin still remains uncertain, though it is presumed that MDT bioaccumulates 520 through dietary consumption. If an algal group is responsible for its production, MDT could 521 serve as a biomarker for its consumption among higher trophic levels, unlike vitamin E, which is 522 somewhat ubiquitous amongst algal groups (Engel et al., unpublished data).

$524 \quad$ Fatty Acids

525 Changes in several fatty acids from water column particles reflected the transition from ice 526 diatoms (LSp-I) to pelagic diatoms (LSp-P) at late spring sampling stations, and then from a 527 heterotroph-dominated station (ESu-I) and back to pelagic diatoms (ESu-P), again, in early 528 summer stations (Fig 4).Cell counts or carbon estimates were not available for ice diatom station 529 LSp-I, but it is known that Fragillariopsis sp. was prominent with some Thalassiosira sp. also 530 present. These ice diatoms often differ in fatty acid composition versus pelagic diatoms; for 531 example, some species of Thalassiosira attribute 19\% of total fatty acids to C20:5(n-3), whereas 532 Chaetoceros, the pelagic diatom dominant at LSp-P, distributes the majority of its fatty acids 533 between C14:0, C16:0, and C16:1(n-7) (Volkman et al., 1989; Viso and Marty, 1993;Vega et al., 534 2010).The C22:6(n-3) PUFA, was highest in abundance at the ice diatom-dominated station LSp- 
535 I (12.8\%) and much lower (0.4-3.0\%) for all other particles samples. Similarly, C20:5(n-3)was

536 also highest at the ice diatom station, but lower in both the water column particles and the krill.

537 While they are not solely markers for ice diatoms, the shift in PUFA relative abundancebetween

538 particle samples does highlight the change in diet throughout the period of ice retreat. Overall,

539 for this Bering Sea system, higher abundances of C20:5(n-3) and C22:6(n-3) seem to indicate a

540 large ice diatom presence whereas higher amounts of the SFAs C14:0n and C16:0n in addition to

541 C16:1(n-7) convey the transition to more pelagic diatoms (e.g. Chaetoceros sp.) and perhaps

542 heterotrophic plankton.

543 Among the 70 different fatty acids identified in both incubation experiments, an unusual C28:8

544 fatty acid was observed in both the water column particles from station ESp-I and the Day 0 T.

545 raschiifeeding incubation (Appendices 2 and 3). The (n-3) moiety of this fatty acid has been

546 observed in autotrophic and heterotrophic dinoflagellates, and prymnesiophytes (Mansour et al.,

547 1999; Van Pelt et al., 1999; Mansour et al., 2005). Interestingly, Antarctic krill have also been

548 known to store this unusual C28 fatty acid (Phleger et al., 2002).Small amounts of C24:1 (n-9), a

549 known copepod marker,wasalso found in all of the early summer animals, but only in some of

550 the late spring animals. The variation in markers between the two krill experiments may indicate

551 differential feeding patterns for these animals that extend outside of the algal regime.

552

$553 \quad$ 4.3 Comparisons with Antarctic Krill Starvation Experiments

554 Incubation experiments that analyze changes in krill lipids over time are more labor-intensive,

555 and thus there are fewer of these types of studies with which to compare our results. There area

556 number ofcommonalities between the species in this study,Thysanoessa raschii, and the

557 Antarctic krillEuphausia superba. Both krill exhibit omnivorous tendencies (Falk-Petersen et 
558 al., 2000).Phospholipids make up the majority of their lipid class distribution; TAG is their

559 primary storage lipid, though phospholipids are also likely contributors; and bothcontain low

560 abundances of wax esters (Sargent and Falk-Petersen, 1981 and references therein; Auerswald et

561 al., 2009; Ju et al., 2009; O’Brien et al., 2011; Harvey et al., 2012). Maximum, summer, and

562 autumn total lipid concentrations, as a percent dry weight,from previous studies were very

563 similar (Falk-Petersen et al., 2000). On that basis, a comparison of general trends in lipid

564 retention and fatty acid distribution between these krill may be reasonable.One short-term

565 starvation experiment (18 days) involving Euphausiia superba, which were collected near the end

566 of austral winter before krill begin to build energy stores, found that total lipid concentrations

567 based on dry weight decreased by $40 \%$ within the first 5 days, largely attributed to decreases in

568 PL and TAG(Auerswald et al., 2009). These results are similar to the present study in which

569 phospholipids (PL) dropped to 43\% of the original concentration for the late spring experiment.

570 While some adjustment is needed for the differences in units (wet verses dry weights) it appears

571 there is commonality in lipid utilization for omnivorous, polar krill during periods of starvation.

572 In a long-term starvation experiment by O’Brien et al. (2011),E. superba were monitored for 207

573 days, subsampling frequently for the first 47 days and then only at day 207. Over the first 26

574 days, individual total lipid decreased by54\%.On a bulk average basis ( mg lipid•ind $^{-1}$ ), there was

575 a35\% decrease in total lipid for the late springT. raschii over by the end of the 31-day period,

576 suggesting that $T$. raschii and E. superba have similar responses to starvation conditions when

577 neither species has had a chance to build up lipid stores. As both of these Antarctic E.

578 superbaexperiments by Auerswald et al (2009) and O’Brien et al (2011) showed, PL was always

579 the dominant lipid, and it gradually increased throughout the course of the experiment as TAG 
580 stores were depleted, a trend similar to what was observed for T. raschiiin the late spring

581 experiment.

582

583 CONCLUSIONS

584 Small, reproductively activeThysanoessa raschiiexhibit considerable lipid loss under starvation

585 conditions within a short period of time.Early summeradults fare better than the smaller, late 586 springadults under similar conditions. During conditions of spring and summer phytoplankton

587 communities, most T. raschii sterol and fatty acid biomarkers maintain a fairly constant relative

588 abundance,despitefluctuations in total lipid after brief periods of feeding.Unless brought upon by

589 long periods of starvation, subtle changes in lipid compositions appear more reflective of life

590 stage than responses to short-term feeding or transient phytoplankton food sources.

591

592 ACKNOWLEDGEMENTS

593 This workwassupportedbytheNationalScience Foundation through

594 theArcticNaturalSciencesprogramtoHRH (ARC-0732667)andEJL (ARC-073289) as part

595 oftheBering Sea Project, with instrumentation support through an MRI award to HRH (OCE-

596 1229197).We would like to thank Jessica Faux and the crew of the R/V Thomas G. Thompson

597 for sampling assistance, Carin Ashjian for assistance with the map figure, Calvin Mordy at

598 NOAA for chlorophyll measurements, and Edward Durbin at the University of Rhode Island for

599 the loan of his Bongo net.ThisisOEASMOGELContribution \#15-002

600 ofOldDominionUniversityand BEST-BSIERP Bering Sea ProjectContribution \#163.

601

602 REFERENCES 
Adams, C.F., Pinchuk, A.I., Coyle, K.O., 2007. Seasonal changes in the diet composition and prey selection of walleye Pollock (Theragra chalcogramma) in the northern Gulf of Alaska. Fish. Res. 84, 378-389.

Agersted, M.D., Nielsen, T.G., Munk, P., Vismann, B., Arendt, K.E., 2011. The functional biology and trophic role of krill (Thysanoessa raschii) in a Greenland fjord. Mar. Biol. 158, 1387-1402.

Amante, C. and B.W. Eakins, 2009. ETOPO1 1 Arc-Minute Global Relief Model: Procedures, Data Sources and Analysis. NOAA Technical Memorandum NESDIS NGDC-24. National Geophysical Data Center, NOAA. Doi:10.7289/V5C8276M, May 18, 2015.

Auerswald, L., Pape, C., Stübing, D., Lopata, A., Meyer, B., 2009. Effect of short-term starvation of adult Antarctic krill, Euphausia superba, at the onset of summer. J. Exp. Mar. Biol. Ecol., 381, 47-56.

Barrett, S.M., Volkman, J.K., Dunstan, G.A., LeRoi, J-M., 1995. Sterols of 14 Species of Marine Diatoms (Bacillariophyta). J. Phycol. 31, 360-369.

Belicka, L.L., Macdonald, R.W., Harvey, H.R., 2002. Sources and transport of organic carbon to shelf, slope, and basin surface sediments of the Arctic Ocean. Deep Sea Res. Pt I. 49(8), 14631483.

Bi, H., Pinchuk, A.I., Harvey, H.R., 2015. Interannual summer variability in euphausiid populations on the eastern Bering Sea shelf during the recent cooling event (2008-2010). Deep Sea Res. I. 95, 12-19.

Dahl, K.A., Repeta, D.J., Goericke, R., 2004. Reconstructing the phytoplankton community of the Cariaco Basin during the Younger Dryas cold event using chlorin steryl esters. Paleoceanography. 19, 1-13.

Destaillats F., Angers P., 2002. One-Step Methodology for the Synthesis of FA PicolinylEsters from Intact Lipids. JAOCS. 79(3), 253-256.

Dunlap,W.C., Fujisawa, A., Yamamoto, Y., Moylan, T.J., Sidell, B.D., 2002. Notothenioid fish, krill and phytoplankton from Antarctica contain a vitamin E constituent ( $\alpha$-tocomonoenol) functionally associated with cold-water adaptation. Comp. Biochem. Phys. Pt. B. 133, 299-305.

Falk-Petersen, S., 1981. Ecological Investigations on the Zooplankton Community of Balsfjorden, Northern Norway: Seasonal Changes in Body Weight and the Main Biochemical Composition of Thysanoessa inermis (Krøyer), T. raschii (M. Sars), and Meganyctiphanes norvegica (M. Sars) in Relation to Environmental Factors. J. Exp. Mar. Biol. Ecol. 49, 103-120.

Falk-Petersen, S., Gatten R.R., Sargent, J.R., Hopkins, C.C.E., 1981. Ecological Investigations on the Zooplankton Community of Balsfjorden, Northern Norway: seasonal changes in lipid 
661

662

663

664

665

666

667

668

669

670

671

672

673

674

675

676

677

678

679

680

681

682

683

684

685

686

687

688

689

690

691

692

693

class composition of Meganyctiphanes norvegica (M. Sars), Thysanoessa raschii (M. Sars) and T. inermis (Krøyer). J. Exp. Mar. Biol. Ecol. 54, 209-224.

Falk-Petersen, S., Hagen, W., Kattner, G., Clarke, A., Sargent, J., 2000. Lipids, trophic relationships, and biodiversity in Arctic and Antarctic krill. Can. J. Fish. Aquat. Sci. 57(Suppl. 3), 178-191.

Ghosh, P., Patterson, G.W., Wikfors, G.H., 1998. Sterols of Some Marine Prymnesiophyceae. J. Phycol. 34, 511-514.

Harvey, H.R., Eglinton, G., O’Hara, S.C.M., Corner, E.D.S, 1987. Biotransformation and assimilation of dietary lipids by Calanus feeding on a dinoflagellate. Geochim. Cosmochim. Acta. 51, 3031-3034.

Harvey, H.R., Pleuthner, R.L., Lessard, E.J., Bernhardt, M.J., Shaw, C.T., 2012. Physical andbiochemicalpropertiesoftheeuphausiids Thysanoessa inermis, Thysanoessa raschii, and Thysanoessa longipes in theeasternBeringSea. Deep-Sea Res. Pt II, 65-70, 173-183.

Harvey, H.R., Sigler, M.F., 2013.An Introduction to the Bering Sea Project: Volume II. Deep Sea Res. Pt II, 94, 2-6.

Ju, S-J, Kang, H-K, Kim, W.S., Harvey, H.R., 2009. Comparative lipid dynamics of euphausiids from the Antarctic and Northeast Pacific Oceans. Mar. Biol. 156, 1459-1473.

Kanazawa, A. 2001. Sterols in Marine Invertebrates. Fisheries Sci. 67, 997-1007.

Lessard, E.J., Murrell, M.C., 1996. Distribution, abundance and size composition of heterotrophic dinoflagellates and ciliates in the Sargasso Sea near Bermuda, Deep Sea Res., Pt I, 43(7), 1045 - 1065.

Mansour, M.P., Volkman, J.K, Jackson, A.E., Blackburn, S.I, 1999. The fatty acid and sterol composition of five marine dinoflagellates. J. Phycol. 35(4), 710-720.

Mansour, M.P., Frampton, D.M.F., Nichols, P.D., Volkman, J.K., Blackburn, S.I., 2005. Lipid and fatty acid yield of nine stationary-phase microalgae: Applications and unusual $\mathrm{C}_{24}-\mathrm{C}_{28}$ polyunsaturated fatty acids. J. Appl. Phycol. 17, 287-300.

Marinovic, B., Mangel, M., 1999. Krill can shrink as an ecological adaptation to temporarily unfavorable environments. Ecology Letters. 2(5), 338-343.

Menden-Deuer, S., Lessard, E.J., 2000. Carbon to volume relationships for dinoflagellates, diatoms, and other protist plankton, Limnol. Oceanogr. 45, 569- 579.

O’Brien, C., Vitrue, P., Kawaguchi, S., Nicols, P.D., 2011. Aspects ofkrillgrowthandconditionduringlatewinter-earlyspringoff East Antarctica(110-1301E). Deep Sea Res. Pt II. 58 (9-10), 1211-1221. 
Phleger, C.F., Nelson, M.M., Mooney, B.D., Nichols, P.D., 2002. Interannual and between species comparison of the lipids, fatty acids and sterols of Antarctic krill from the US AMLR Elephant Island survey area. Comp. Biochem Phys B. 131(4), 733-747.

Pinchuk, A.I., Coyle, K.O., 2008. Distribution, egg production and growth of euphausiids in the vicinity of the Pribilof Islands, southeastern Bering Sea, August 2004. Deep-Sea Res. Pt. II. 55, 1792-1800.

Rampen, S.W., Abbas, B.A., Schouten, S., Sinninghe Damasté, J.S., 2010. A comprehensive study of sterols in marine diatoms (Bacillariophyta): Implications for their use as tracers for diatom productivity. Limnol. Oceanogr. 55(1), 91-105.

Roff, J. C., Hopcroft, R.R.,1986. High precision microcomputer based measuring system for ecological research, Can. J. Fish. Aquat. Sci. 43, 2044- 2048.

Rontani,J.F., Bonin, P.C., Volkman, J.K., 1999. Production of Wax Esters during Aerobic Growth of Marine Bacteria on Isoprenoid Compounds. Appl. Environ. Microb. 65(1), 221-230.

Sargent, J.R., Falk-Petersen, S., 1981. Ecological Investigations on the Zooplankton Community of Balsfjorden, Northern Norway: lipids and fatty acids in Meganyctiphanes norvegica, Thysanoessa raschii and Thysanoessa inermis during mid-winter. Mar. Biol. 62, 131-137.

Shaw, C.T., Peterson, W.T., Feinberg, L.R., 2010. Growth of Euphausia pacifica in the upwelling zone off the Oregon coast. Deep-Sea Res. Pt. II. 57, 584-593.

Smith, S.L., 1991. Growth, development and distribution of the euphausiids Thysanoessa raschii (M. Sars) and Thysanoessa inermis (Krøyer) in the southeastern Bering Sea. Polar Res. 10(2), 461-478.

Thompson, P.G., Wright, S.W., Bolch, C.J., Nichols, P.D., Skerratt, J.H., McMinn, A., 2004. Antarctic distribution, pigment and lipid composition, and molecular identification of the brine dinoflagellate Polarella glacialis (Dinophyceae). J. Phycol. 40, 867-873.

Tsitsa-Tzardis, E., Patterson, G.W., Wikfors, G.H., Gladu, P.K., Harrison, D., 1993. Sterols ofChaetoceros andSkeletonema. Lipids. 28(5), 465-467.

Van Pelt, C.K., Huang, M-C, Tschanz, C.L., Brenna, J.T., 1999. An octaene fatty acid, 4,7,10,13,16,19,22,25-octacosaoctaenoic acid (28:8n-3), found in marine oils. J. Lipid Res. 40, 1501-1505.

Vega, J.M.P., Roa, M.A.C. Saavedra, M.d.P.S., Ramírez, D.T., Dávalos, C.R., 2010. Effect of culture medium and nutrient concentration on fatty acid content of Chaetoceros muelleri. Latinoam Biotecnol Amb Algal. 1(1), 6-15. 
739 Viso A-C., Marty, J-C., 1993. Fatty Acids from 28 Marine Microalgae. Phytochem. 34(6), 15217401533.

741

742 Volkman, J.K., 1986. A review of sterol markers for marine and terrigenous organic matter. Org. 743 Geochem. 9(2), 83-99.

745 Volkman, J.K., Jeffrey, S.W., Nichols, P.D., Rogers, G.I., Garland, C.D., 1989. Fatty acid and

746 lipid composition of 10 species of microalgae used in mariculture. J. Exp. Mar. Biol. Ecol. 128:

$747 \quad 219-240$.

748

749 Withers N.W., Nevenzel J.C.,1977. Phytyl Esters in a Marine Dinoflagellate. Lipids. 12(12), 750 989-993.

751

752

753

754

Worden, A. Z., Nolan,J. K., B. Palenik, B., 2004. Assessing the dynamics and ecology of marine picophytoplankton: The importance of the eukaryotic component, Limnol. Oceanogr., 49, 168179.

755

756

757

758

759

760

761

762

763

764

765

766

767

768

769

770 


\section{Figure \& Table Legends}

\section{Figure 1}

Stations sampled for late spring (LSp) and early summer (ESu) pulsed-feeding experiments (map from ETOPO1). Locations at which $T$. raschii and water column particle samples were collected for the initiation of each experiment (-I); locations at which whole water was collected for feeding pulses and particle samples (-P).

Figure 2

Experimental scheme for both krill incubations. Day x (y) indicates the days on which the krill were subsampled where $\mathrm{x}$ corresponds to the late spring experiment and (y) to the early summer experiment. The removal of krill for each subsample is indicated by the downward arrow to the krill timepoint. Shaded box indicates the addition of the water column food pulse.

Figure 3

Total lipid normalized to wet weight ( $\mathbf{O}$ ) during late spring (top) and early summer (bottom) $T$. raschii pulsed feeding experiments (A). Corresponding lipid class abundances for each time point are also shown (B). In 'A', numbers in parentheses indicate the number of krill in each composite. The arrows above the graph indicate periods of starvation (FSW = filtered sea water) or feeding $(\mathrm{WC}=$ water column pulse). The area between the two dashed lines corresponds to the pulse food period. In 'B', lipid classes are denoted as follows: PL = phospholipid; ST = sterols; FFA = free fatty acids; TAG = triacylglycerols; WE = wax esters.

Figure 4

Fatty acid relativeabundance in krill and particle samplesthroughout each feeding experiment. Particle columns are noted by their sampling station name; krill are indicated by the numeric day they were sampled. Fatty acids present at $<5 \%$ in krill are excluded for brevity. Pie charts above each bar indicate the percentage of SFA (white), MUFA (black), and PUFA (gray) of total FA in each sample. Note: C18:4(n-3) accounted for 6\% of FA at LSp-I, but was $\leq 2 \%$ in all other krill and particle samples, and was therefore excluded from the graph.*Krill after 3 days of grazing on water column (WC) particle additions.

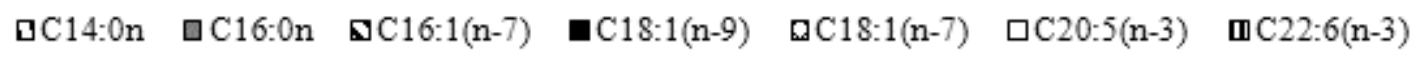

Figure 5

Multi-dimensional scaling (MDS) plots of relative abundance of lipid classes for all T. raschii subsamples (A), sterols abundances in T. raschii and particle samples (B), and fatty acids abundances for krill and particle samples (C). Krill from late spring (LSp-) and early summer (ESu-) have labels appended with their subsampled time point $\left(\mathrm{T}_{0}\right.$ through $\mathrm{T}_{\mathrm{f}} ; 6$ subsamples in total for each experiment). Water column particles from late spring (LSp) and early summer (ESu) are appended with -I for the initial sampling time or -P indicating it was a food pulse. The ellipses represent the groupings that fall into a dissimiliarity level of $5 \%$ in A, and $30 \%$ in B and C.

\section{Table 1}


Summary information forthe four sites used for animal and particlesincubation experiments. Chl refers to surface chlorophyll. POC and PN numbers correspond to measurements taken at the particle collection depths.

\section{Table 2}

Algal taxa abundance and estimated biomass for the four sites at which qualitative and quantitative data were available. (Only qualitative FlowCAM data was available from station LSP-I.)*Ciliates include mixotrophs.

\section{Table 3}

Relative abundances of neutral lipids for both particle and T. raschii samplesthroughout both the late spring (LSp) and early summer (ESu) experiments. Total neutral concentrations for all samples are listed. “”" indicates below detection limits; tr=Trace (Abundance $<0.1 \%$ of neutral lipids); *Particle samples only contained $\alpha$-tocopherol.

\section{Table 4}

The relative abundances of sterols in water column particles (shaded columns) and each krillsubsampleduring the late spring (LSp)experiment. Bolded sterols are observed in both krill and water column particles. "”" indicates absent or below detection limits; $\mathrm{tr}=$ Trace (Abundance $<0.1 \%)$; ${ }^{1}$ sterols coelute; ${ }^{2}$ isomers coelute, but the unknown only in particle samples; *sterols that accounted for $<0.5 \%$ relative abundance in krill and particles (cholest-7-en-3 $\beta$-ol; cholest5,7-dien-3 $\beta$-ol; and 24-methylcholest-7-en-3 $\alpha$-ol) were omitted for brevity.

\section{Table 5}

The relative abundances of sterols in water column particles (shaded columns) and each krill sub-sample during the early summer (ESu) experiment. Bolded sterols are observed in both krill and water column particles. "’" indicates absent or below detection limits; $\mathrm{tr}$ = Trace (Abundance $<0.1 \%$ ); ${ }^{1}$ sterols coelute; ${ }^{2}$ isomers coelute, but the unknown only in particle samples;*sterols that accounted for $<0.5 \%$ relative abundance in krill and particles (cholest-7-en-3 $\beta$-ol; cholest-5,7,22trien-3 $\beta$-ol; 24-methylcholest-7-en-3 $\alpha$-ol; 24-methylcholest-24(28)-en-3 $\beta$-ol; 23,24dimethylcholest-5,22-dien-3 $\beta$-ol;24-ethylcholest-7-en-3 $\beta$-ol; and24-propylcholest-5,24-dien-3 $\beta$ ol,) were omitted for brevity.

\section{Appendix 1}

Physiological information regarding the T. raschii krill composites for the late spring and early summer experiments.

\section{Appendix 2}

Total fatty acid concentration and percent composition of individual fatty acids in particle samples (shaded columns) and all krill sub-samples taken throughout the late springexperiment. Fatty acids seen in both the water column and krill samples are in bold. $\backslash$ = absent or below detection limits; tr = Trace (Relative abundance $<0.1 \%$ ); *inclusion of multiple isomers. Fatty acids present in trace abundance in particles only were excluded for brevity and include C12:0n, C13:0i, C13:0a, C13:0n, C14:0a, C23:0n, and C26:0n.

\section{Appendix 3}


861 Total fatty acid concentration and percent composition of individual fatty acids in particle

862 samples (shaded columns) and all krill sub-samples taken throughout the early summer

863 experiment.Fatty acids seen in both the water column and krill samples are in bold. $\backslash=$ absent or

864 below detection limits;tr $=$ Trace $($ Relative abundance $<0.1 \%$ ); $*$ inclusion of multiple isomers.

865 Fatty acids present in trace abundance in particles only were excluded for brevity and include

866 C12:0n, C13:0i, C14:0a, C26:0n, and C26:1. 


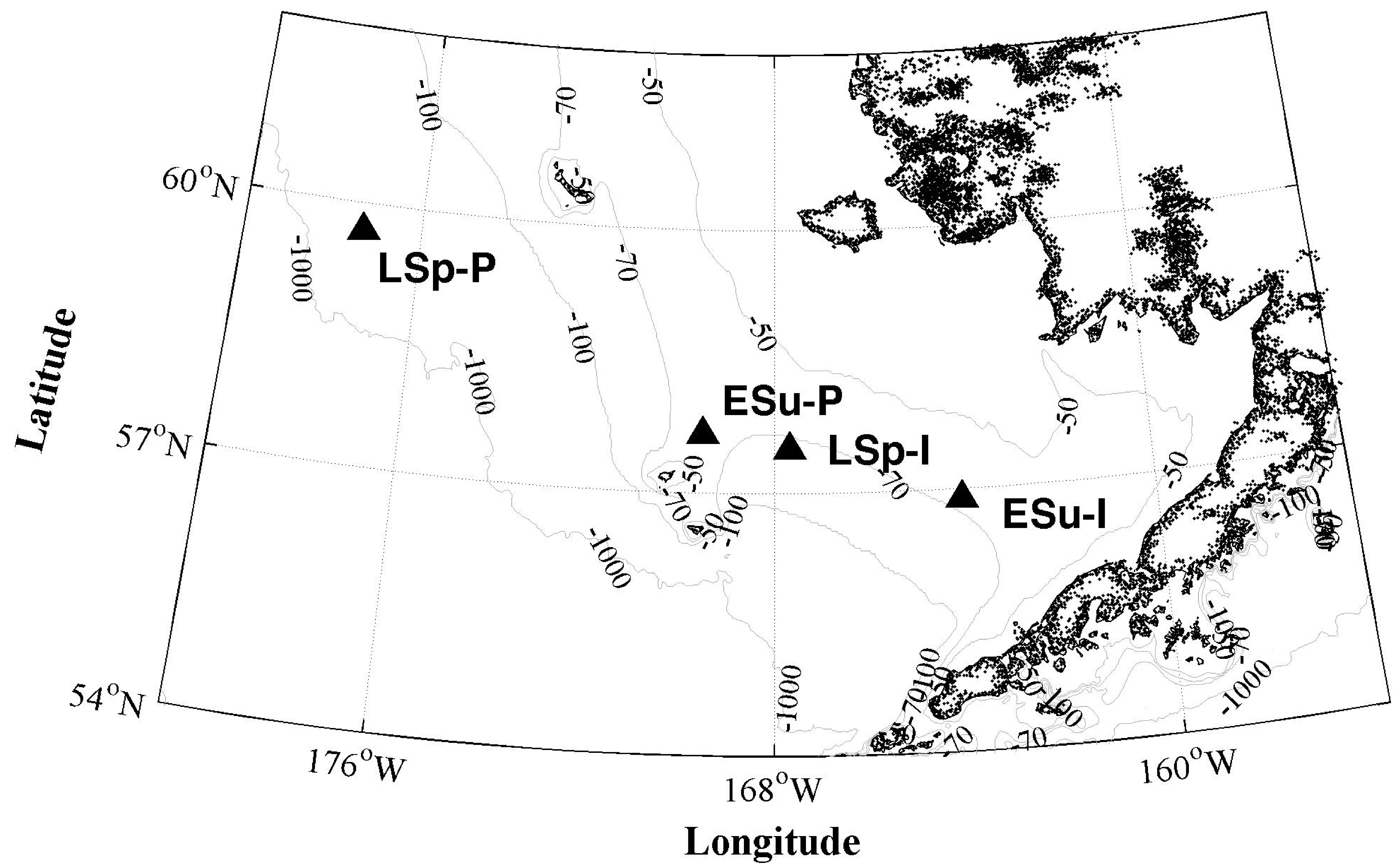


Late

Spring

Early Summer
FSW

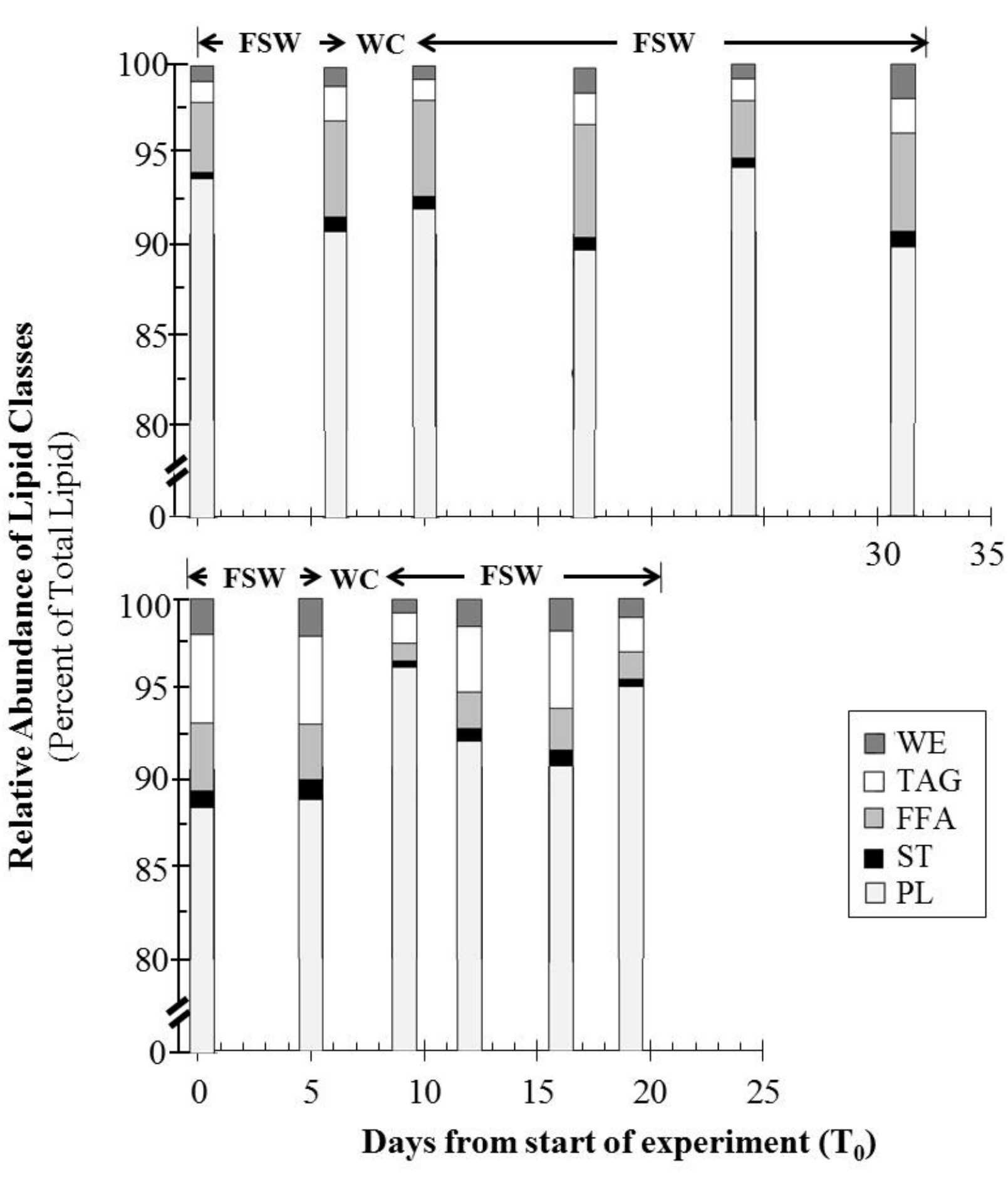




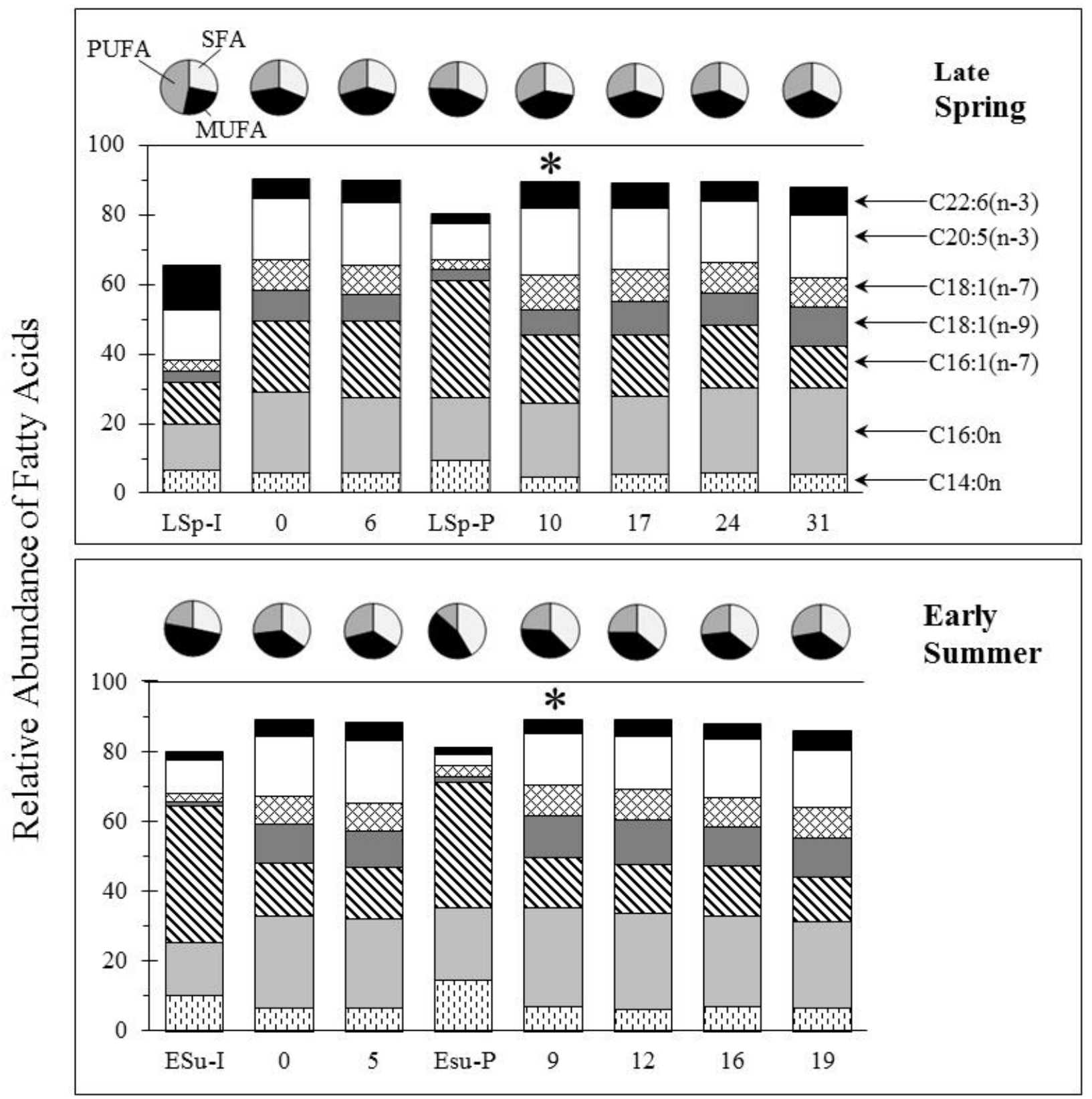

Krill subsamples (days) and Associated Particle Samples 

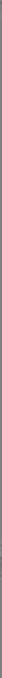

All krill

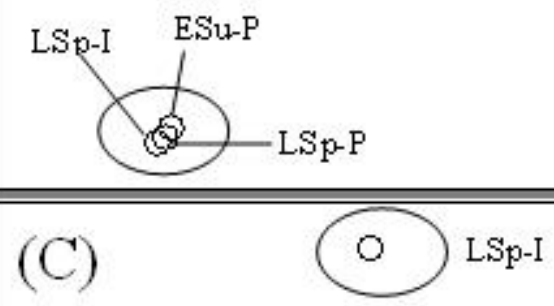

All krill
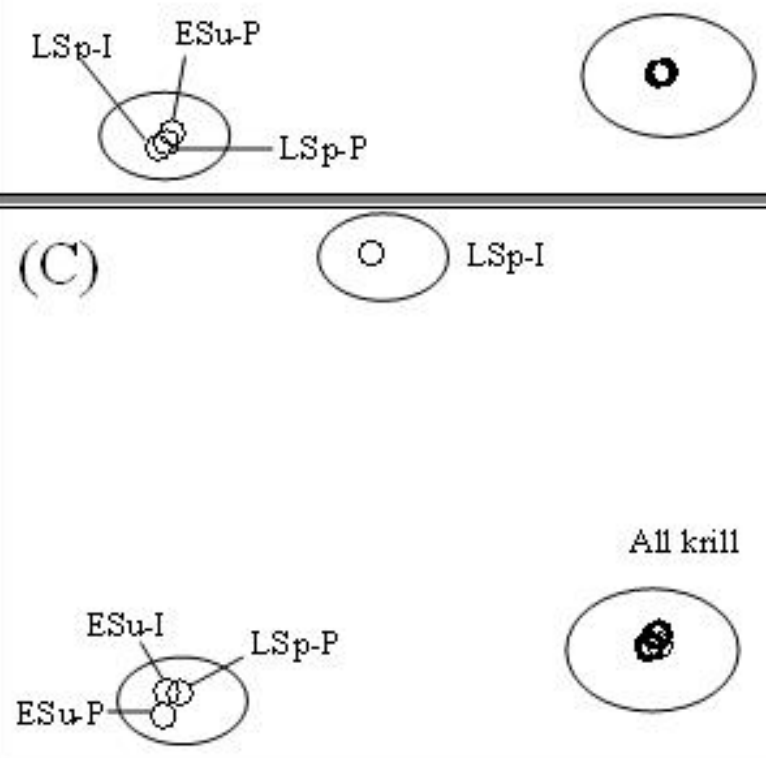


\begin{tabular}{l|rr|rr}
\cline { 2 - 5 } & \multicolumn{4}{c}{ Sampling Stations } \\
\hline Particle Sample Name & \multicolumn{1}{c}{ LSp-I } & LSp-P & ESu-I & ESu-P \\
\hline Cruise Name & TN249 & TN249 & TN250 & TN250 \\
Date & $6 / 1 / 2010$ & $6 / 8 / 2010$ & $6 / 20 / 2010$ & $6 / 25 / 2010$ \\
Station Name, No. & $70 \mathrm{M} 16,111$ & EV-7, 168 & CN-6, 19 & NP-8, 46 \\
Latitude $\left({ }^{\circ}\right)$ & 57.5001 & 59.6867 & 56.8921 & 57.6650 \\
Longitude $\left({ }^{\circ}\right)$ & 167.6651 & 177.2954 & 164.0591 & 169.5217 \\
Station Depth $(\mathrm{m})$ & 72 & 185 & 122 & 71 \\
Tow Depth $(\mathrm{m})$ & 46 & $\mathrm{~N} / \mathrm{A}$ & 57 & $\mathrm{~N} / \mathrm{A}$ \\
Particle Collection Depth $(\mathrm{m})$ & 20 & 23 & 30 & 23 \\
Temp $\left({ }^{\circ} \mathrm{C}\right)$ & -0.9 & 0.1 & 3.0 & 2.1 \\
Chl $(\mu \mathrm{g} / \mathrm{L})$ & 5.52 & 4.41 & 0.74 & 3.99 \\
POC, $\mathrm{n}=2(\mu \mathrm{g} / \mathrm{L})$ & $286 \pm 5$ & $287 \pm 16$ & $170 \pm 97$ & $659 \pm 75$ \\
PN, $\mathrm{n}=2(\mu \mathrm{g} / \mathrm{L})$ & $60 \pm 1$ & $56 \pm 3$ & $44 \pm 22$ & $131 \pm 23$ \\
POC/PN & 4.77 & 5.13 & 3.86 & 5.03 \\
\hline
\end{tabular}

Pleuthner et al. Table 1 


\begin{tabular}{|c|c|c|c|c|c|c|c|c|c|c|c|c|}
\hline \multirow[b]{2}{*}{$\begin{array}{l}\text { Plankton } \\
\text { Group }\end{array}$} & \multicolumn{4}{|c|}{ Abundance $\left(\right.$ cell $\left.\cdot \mathrm{mL}^{-1}\right)$} & \multicolumn{4}{|c|}{ Estimated Biomass $\left(\mu \mathrm{g} \mathrm{C} \cdot \mathrm{L}^{-1}\right)$} & \multicolumn{4}{|c|}{ Percent Estimated Biomass (\%) } \\
\hline & LSp-I & LSp-P & ESu-I & ESu-P & LSp-I & LSp-P & ESu-I & ESu-P & LSp-I & LSp-P & ESu-I & ESu-P \\
\hline \multicolumn{13}{|l|}{ Autotrophs } \\
\hline Diatoms & - & 853 & 9 & 2308 & - & 64 & 0.5 & 85.4 & - & 76.5 & 2.6 & 59.7 \\
\hline Dinoflagellates & - & 8 & 28 & 2 & - & 0.7 & 1.0 & 0.7 & - & 0.8 & 5.3 & 0.5 \\
\hline Nanoflagellates & - & 278 & 3174 & 618 & - & 0.8 & 5.3 & 0.9 & - & 1.0 & 27.9 & 0.6 \\
\hline Picoeukaryotes & - & 168 & 264 & 3037 & - & 0.2 & 0.3 & 3.1 & - & 0.2 & 1.6 & 2.2 \\
\hline Cyanobacteria & - & 0 & 86 & 391 & - & 0 & 0 & 0.1 & - & 0 & 0 & 0.1 \\
\hline \multicolumn{13}{|l|}{ Heterotrophs } \\
\hline Dinoflagellates & - & 39 & 51 & 27 & - & 5.7 & 1.6 & 26.4 & - & 6.8 & 8.4 & 18.5 \\
\hline Ciliates* & - & 7 & 3 & 3 & - & 9.4 & 0.9 & 21.2 & - & 11.2 & 4.7 & 14.9 \\
\hline Nanoflagellates & - & 587 & 3820 & 2074 & - & 2.9 & 9.4 & 5.0 & - & 3.5 & 49.5 & 3.5 \\
\hline Total & - & 1940 & 7438 & 8760 & - & 84 & 19 & 143 & - & 100 & 100 & 100 \\
\hline
\end{tabular}

Pleuthner et al. Table 2 
Neutral Lipid Composition

\begin{tabular}{|c|c|c|c|c|c|c|c|c|}
\hline \multirow[b]{2}{*}{ Late Spring (LSp) } & LSp-I & LSp- $T_{0}$ & LSp- $T_{1}$ & LSp-P & LSp- $\mathrm{T}_{2}$ & $\mathrm{LSp}-\mathrm{T}_{3}$ & $\mathrm{LSp}-\mathrm{T}_{4}$ & $L S p-T_{f}$ \\
\hline & Day 0 & Day 0 & Day 6 & $\begin{array}{l}\text { Day } 6 \\
\text { (post } T_{1} \text { ) }\end{array}$ & Day 10 & Day 17 & Day 24 & Day 31 \\
\hline Alcohols & 34.5 & 1.5 & 1.9 & 61.4 & 1.5 & 2.7 & 1.3 & 3.2 \\
\hline Phytol & 45.6 & 46.9 & 35.8 & 20.0 & 31.1 & 43.5 & 46.2 & 48.4 \\
\hline Sterols & 19.1 & 49.1 & 58.4 & 18.3 & 62.9 & 50.0 & 49.2 & 44.9 \\
\hline Tocopherols* & $\operatorname{tr}$ & 1.7 & 3.3 & $\operatorname{tr}$ & 3.2 & 3.1 & 2.6 & 2.7 \\
\hline Waxes & 1 & 0.3 & 0.1 & 1 & $\operatorname{tr}$ & $\operatorname{tr}$ & $\operatorname{tr}$ & 0.1 \\
\hline Glycerol Monoethers & 0.8 & 0.5 & 0.5 & 0.2 & 1.3 & 0.7 & 0.7 & 0.8 \\
\hline Summed Relative Abundance & 100 & 100 & 100 & 100 & 100 & 100 & 100 & 100 \\
\hline $\begin{array}{l}\text { Krill neutral lipid conc. } \\
\text { ( } \mu \mathrm{g} \mathrm{lipid} / \mathrm{g} W W)\end{array}$ & \multirow[b]{2}{*}{14.6} & \multirow[t]{2}{*}{1888.7} & \multirow[t]{2}{*}{1666.5} & \multirow[b]{2}{*}{21.7} & \multirow[t]{2}{*}{1201.8} & \multirow[t]{2}{*}{1963.5} & \multirow[t]{2}{*}{1975.1} & \multirow[t]{2}{*}{2027.5} \\
\hline $\begin{array}{l}\text { Particle neutral lipid conc. } \\
\text { (mg lipid/g OC) }\end{array}$ & & & & & & & & \\
\hline \multirow[b]{2}{*}{ Early Summer (ESu) } & ESu-I & ESu- $T_{0}$ & ESu- $\mathrm{T}_{1}$ & ESu-P & ESu- $\mathrm{T}_{2}$ & $\mathrm{ESu} \mathrm{T}_{3}$ & ESu- $\mathrm{T}_{4}$ & ESu- $T_{f}$ \\
\hline & Day 0 & Day 0 & Day 5 & $\begin{array}{c}\text { Day } 5 \\
\left(\text { post } T_{1}\right)\end{array}$ & Day 11 & Day 18 & Day 25 & Day 32 \\
\hline Alcohols & 70.2 & 2.5 & 4.3 & 23.9 & 1.9 & 2.9 & 3.9 & 3.0 \\
\hline Phytol & 6.6 & 54.5 & 54.4 & 24.6 & 63.3 & 60.8 & 54.2 & 62.9 \\
\hline Sterols & 21.2 & 33.1 & 36.3 & 50.2 & 31.7 & 29.6 & 32.4 & 30.6 \\
\hline Tocopherols* & $\operatorname{tr}$ & 2.5 & 2.7 & $\operatorname{tr}$ & 2.3 & 2.5 & 2.1 & 2.3 \\
\hline Waxes & 1 & 6.5 & 1.5 & 1 & 0.3 & 3.6 & 6.6 & 0.7 \\
\hline Glycerol Monoethers & 1.9 & 0.9 & 0.8 & 1.3 & 0.5 & 0.7 & 0.8 & 0.4 \\
\hline Summed Relative Abundance & 100 & 100 & 100 & 100 & 100 & 100 & 100 & 100 \\
\hline $\begin{array}{l}\text { Krill neutral lipid conc. } \\
(\mu \mathrm{g} \mathrm{lipid/g} \mathrm{WW)}\end{array}$ & \multirow[b]{2}{*}{24.4} & \multirow[t]{2}{*}{3109.4} & \multirow[t]{2}{*}{2655.9} & \multirow[b]{2}{*}{7.1} & \multirow[t]{2}{*}{2787.8} & \multirow[t]{2}{*}{3560.1} & \multirow[t]{2}{*}{3094.7} & \multirow[t]{2}{*}{3482.7} \\
\hline $\begin{array}{l}\text { Particle neutral lipid conc. } \\
\text { (mg lipid/g OC) }\end{array}$ & & & & & & & & \\
\hline
\end{tabular}

Pleuthner et al. Table 3 


\begin{tabular}{|c|c|c|c|c|c|c|c|c|}
\hline \multirow{2}{*}{$\begin{array}{c}\text { Sterols } \\
\text { (Late Spring) }\end{array}$} & $\begin{array}{l}\text { LSp- } \\
\text { I }\end{array}$ & $\begin{array}{c}\text { LSp- } \\
\mathrm{T}_{0}\end{array}$ & $\begin{array}{c}\text { LSp- } \\
\mathrm{T}_{1}\end{array}$ & LSp-P & $\begin{array}{c}\text { LSp- } \\
\mathrm{T}_{2}\end{array}$ & $\begin{array}{c}\text { LSp- } \\
\mathrm{T}_{3}\end{array}$ & $\begin{array}{c}\text { LSp- } \\
\mathrm{T}_{4}\end{array}$ & $\begin{array}{c}\text { LSp- } \\
\mathrm{T}_{\mathrm{f}}\end{array}$ \\
\hline & $\begin{array}{c}\text { Day } \\
0\end{array}$ & Day 0 & Day 6 & $\begin{array}{c}\text { Day } 6 \\
\text { (post } T_{1} \text { ) }\end{array}$ & $\begin{array}{l}\text { Day } \\
10\end{array}$ & $\begin{array}{c}\text { Day } \\
17\end{array}$ & $\begin{array}{l}\text { Day } \\
24\end{array}$ & $\begin{array}{c}\text { Day } \\
31\end{array}$ \\
\hline 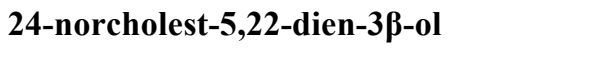 & 11.8 & 0.2 & 0.1 & 9.8 & $\operatorname{tr}$ & $\operatorname{tr}$ & tr & $\operatorname{tr}$ \\
\hline 27-nor-24-cholest-5,22-dien-3ß-ol & 0.7 & 0.7 & 0.6 & 0.7 & 0.4 & 0.3 & 0.1 & 0.2 \\
\hline 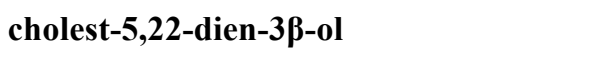 & 6.3 & $\operatorname{tr}$ & $\operatorname{tr}$ & 5.3 & $\operatorname{tr}$ & tr & $\operatorname{tr}$ & tr \\
\hline cholest-5-en-3ß-ol & 10.2 & 90.5 & 94.0 & 13.8 & 95.8 & 94.5 & 96.2 & 96.2 \\
\hline 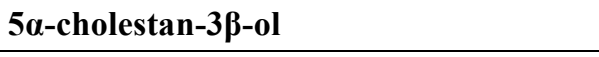 & 0.7 & 0.2 & 0.2 & 0.5 & 0.3 & 0.3 & 0.3 & 0.3 \\
\hline 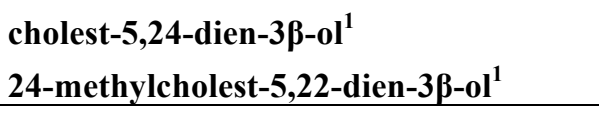 & 26.1 & 7.5 & 4.4 & 17.4 & 2.9 & 4.2 & 2.8 & 2.6 \\
\hline 24-methylcholest-22-en-3 $\beta$-ol & 0.6 & 1 & 1 & 0.3 & 1 & 1 & 1 & 1 \\
\hline 24-methylcholest-5,7,22-triene-3 $\beta$-ol & 0.8 & 1 & 1 & 0.4 & 1 & 1 & 1 & 1 \\
\hline 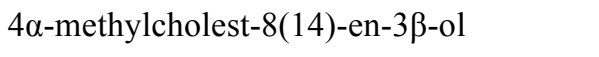 & 0.7 & 1 & 1 & 1.0 & 1 & 1 & 1 & 1 \\
\hline 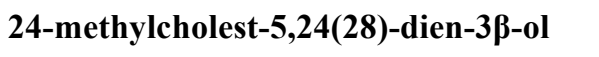 & 28.1 & 0.4 & 0.2 & 39.0 & 0.2 & 0.2 & 0.1 & 0.1 \\
\hline 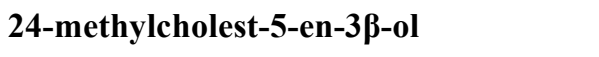 & 2.2 & 0.1 & 0.1 & 1.3 & tr & 0.1 & tr & 0.1 \\
\hline 24-methylcholest-24(28)-en-3 $\beta$-ol & 0.4 & 1 & 1 & 1.1 & 1 & 1 & 1 & 1 \\
\hline 23,24-dimethylcholest-5,22-dien-3 $\beta$-ol & 1.1 & 1 & 1 & 0.5 & 1 & 1 & 1 & 1 \\
\hline 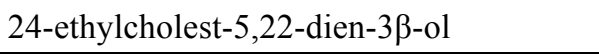 & 0.6 & 1 & 1 & 0.6 & 1 & 1 & 1 & 1 \\
\hline 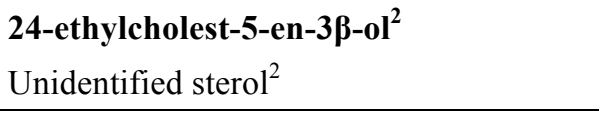 & 2.8 & 0.1 & 0.1 & 1.8 & $\operatorname{tr}$ & $\operatorname{tr}$ & tr & tr \\
\hline 24-ethylcholestan-3 $\beta$-ol & 1.3 & 1 & 1 & 0.6 & 1 & 1 & 1 & 1 \\
\hline 24-ethylcholest-5,24(28)-dien-3 $\beta$-ol & 2.4 & 1 & 1 & 2.2 & 1 & 1 & 1 & 1 \\
\hline $4 \alpha, 23,24$-trimethylcholest-22-en-3 $\beta$-ol & 0.6 & 1 & 1 & 1.0 & 1 & 1 & 1 & 1 \\
\hline 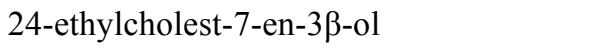 & 0.3 & 1 & 1 & 0.5 & 1 & 1 & 1 & 1 \\
\hline 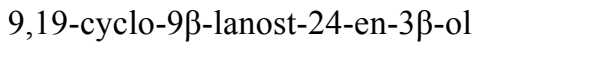 & 0.7 & 1 & 1 & 0.6 & 1 & 1 & 1 & 1 \\
\hline $4 \alpha, 23,24$-trimethylcholest- $8(14)$-en-3 $\beta$-ol & 1.2 & 1 & 1 & 1.0 & 1 & 1 & 1 & 1 \\
\hline Other* & 0.4 & 0.3 & 0.3 & 0.6 & 0.3 & 0.3 & 0.4 & 0.4 \\
\hline SUM: & 100 & 100 & 100 & 100 & 100 & 100 & 100 & 100 \\
\hline
\end{tabular}

Pleuthner et al. Table 4 


\begin{tabular}{|c|c|c|c|c|c|c|c|c|}
\hline \multirow{2}{*}{$\begin{array}{c}\text { Sterols } \\
\text { (Early Summer) }\end{array}$} & $\begin{array}{c}\text { ESu- } \\
\text { I }\end{array}$ & $\begin{array}{c}\text { ESu- } \\
\mathrm{T}_{0}\end{array}$ & $\begin{array}{c}\text { ESu- } \\
\mathrm{T}_{1}\end{array}$ & ESu-P & $\begin{array}{c}\text { ESu- } \\
\mathrm{T}_{2}\end{array}$ & $\begin{array}{c}\text { ESu- } \\
\mathrm{T}_{3}\end{array}$ & $\begin{array}{c}\text { ESu- } \\
\mathrm{T}_{4}\end{array}$ & $\begin{array}{c}\text { ESu- } \\
T_{f}\end{array}$ \\
\hline & $\begin{array}{c}\text { Day } \\
0\end{array}$ & Day 0 & Day 5 & $\begin{array}{c}\text { Day } 5 \\
\text { (post T1) }\end{array}$ & Day 9 & $\begin{array}{l}\text { Day } \\
12\end{array}$ & $\begin{array}{c}\text { Day } \\
16\end{array}$ & $\begin{array}{c}\text { Day } \\
19\end{array}$ \\
\hline 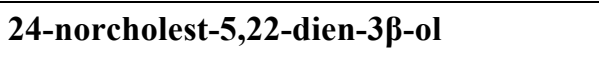 & 17.4 & 0.1 & 0.1 & 9.8 & tr & $\operatorname{tr}$ & tr & tr \\
\hline 27-nor-24-cholest-5,22-dien-3ß-ol & 2.7 & 0.3 & 0.4 & 0.7 & 0.2 & 0.2 & 0.1 & 0.3 \\
\hline 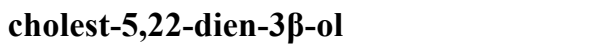 & 14.7 & tr & tr & 4.6 & 0.1 & $\operatorname{tr}$ & tr & tr \\
\hline 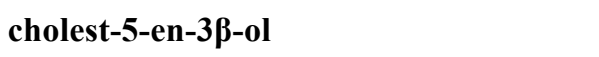 & 21.9 & 91.1 & 92.4 & 26.7 & 91.8 & 91.3 & 92.7 & 92.8 \\
\hline 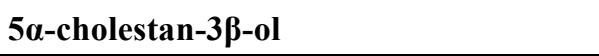 & 0.8 & 0.1 & 0.3 & 0.5 & 0.2 & 0.3 & 0.2 & 0.2 \\
\hline 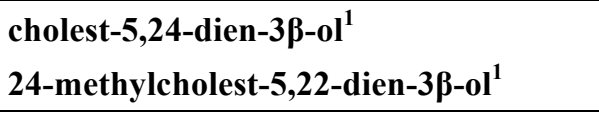 & 20.6 & 7.4 & 5.9 & 7.3 & 6.8 & 7.2 & 6.2 & 6.0 \\
\hline cholest-5,7-dien-3ß-ol & 1.8 & 0.1 & 0.2 & 1 & 0.3 & 0.3 & 0.3 & 0.2 \\
\hline 24-methylcholest-22-en-3 $\beta$-ol & 0.4 & 1 & 1 & 0.9 & 1 & 1 & 1 & 1 \\
\hline 24-methylcholest-5,7,22-triene-3 $\beta$-ol & 2.2 & 1 & 1 & 0.7 & 1 & 1 & 1 & 1 \\
\hline 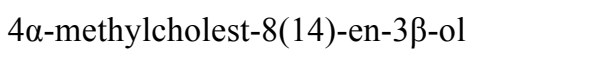 & 2.6 & 1 & 1 & 1.3 & 1 & 1 & 1 & 1 \\
\hline 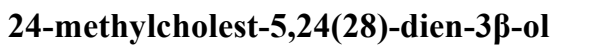 & 6.2 & 0.2 & 0.2 & 38.3 & 0.1 & 0.2 & 0.1 & 0.1 \\
\hline 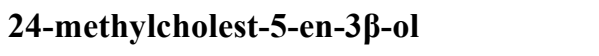 & 0.8 & 0.3 & 0.2 & 1.0 & 0.2 & 0.2 & 0.2 & 0.1 \\
\hline 24-ethylcholest-5,22-dien-3ß-ol & 0.5 & 1 & 1 & 0.4 & 1 & 1 & 1 & 1 \\
\hline 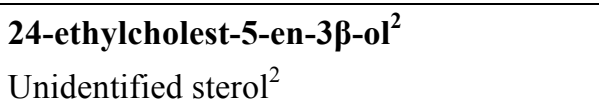 & 2.0 & $\operatorname{tr}$ & $\operatorname{tr}$ & 1.2 & tr & tr & $\operatorname{tr}$ & tr \\
\hline 24-ethylcholestan-3 $\beta$-ol & 0.4 & 1 & 1 & 0.6 & 1 & 1 & 1 & 1 \\
\hline 24-ethylcholest-5,24(28)-dien-3 $\beta$-ol & 2.4 & 1 & 1 & 3.7 & 1 & 1 & 1 & 1 \\
\hline $4 \alpha, 23,24$-trimethylcholest-22-en-3 $\beta$-ol & 0.6 & 1 & 1 & 0.4 & 1 & 1 & 1 & 1 \\
\hline 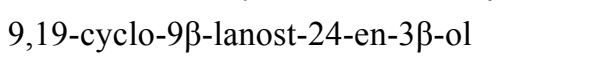 & 0.6 & 1 & 1 & 0.4 & 1 & 1 & 1 & 1 \\
\hline $4 \alpha, 23,24$-trimethylcholest- $8(14)$-en-3 $\beta$-ol & 0.6 & 1 & 1 & 0.9 & 1 & 1 & 1 & 1 \\
\hline Other* & 0.8 & 0.2 & 0.2 & 0.6 & 0.2 & 0.2 & 0.1 & 0.2 \\
\hline SUM: & 100 & 100 & 100 & 100 & 100 & 100 & 100 & 100 \\
\hline
\end{tabular}

Pleuthner et al. Table 5 


\begin{tabular}{|c|c|c|c|c|c|c|}
\hline \multicolumn{7}{|c|}{ Late Spring } \\
\hline Krill Sample & LSp- $\mathrm{T}_{0}$ & LSp- $T_{1}$ & LSp- $\mathrm{T}_{2}$ & $\mathrm{LSp}-\mathrm{T}_{3}$ & LSp- $\mathrm{T}_{4}$ & $L S p-T_{f}$ \\
\hline Time Point & Day 0 & Day 6 & Day 10 & Day 17 & Day 24 & Day 31 \\
\hline Avg Total Length (mm) & $19.21 \pm 1.02$ & $20.93 \pm 2.55$ & $20.80 \pm 2.08$ & $19.84 \pm 0.75$ & $19.18 \pm 1.00$ & $18.62 \pm 1.94$ \\
\hline No. composited krill & 10 & 6 & 4 & 3 & 3 & 4 \\
\hline Avg Wet Weight (mg/ind) & 65.8 & 96.1 & 91.5 & 68.3 & 64.7 & 54.9 \\
\hline Total Lipid Conc (mg lipid/g WW) & 112.2 & 48.8 & 71.3 & 82.8 & 70.2 & 47.4 \\
\hline \multicolumn{7}{|c|}{ Early Summer } \\
\hline Krill Sample & $\mathrm{ESu} \mathrm{T}_{0}$ & $\mathrm{ESu} \mathrm{T}_{1}$ & $\mathrm{ESu}-\mathrm{T}_{2}$ & $\mathrm{ESu} \mathrm{T}_{3}$ & $\mathrm{ESu} \mathrm{T}_{4}$ & $\mathrm{ESu}_{\mathrm{f}}$ \\
\hline Time Point & Day 0 & Day 5 & Day 9 & Day 12 & Day 16 & Day 19 \\
\hline Avg Total Length (mm) & $21.55 \pm 1.75$ & $24.06 \pm 2.08$ & $22.46 \pm 1.52$ & $21.94 \pm 0.88$ & $22.19 \pm 0.48$ & $23.04 \pm 1.08$ \\
\hline No. composited krill & 10 & 8 & 4 & 3 & 3 & 4 \\
\hline Avg Wet Weight (mg/ind) & 97.7 & 136.2 & 135.9 & 105.2 & 103.3 & 110.6 \\
\hline Total Lipid Conc (mg lipid/g WW) & 139.6 & 115.5 & 189.5 & 170.8 & 142.9 & 166.8 \\
\hline
\end{tabular}

Pleuthner et al. Appendix 1

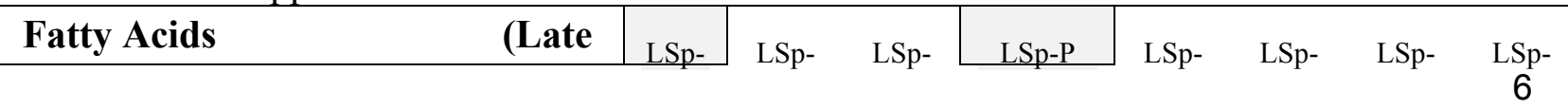




\begin{tabular}{|c|c|c|c|c|c|c|c|c|}
\hline \multirow{3}{*}{ Spring) } & I & $\mathrm{T}_{0}$ & $\mathrm{~T}_{1}$ & LSp-P & $T_{2}$ & $\mathrm{~T}_{3}$ & $\mathrm{~T}_{4}$ & $\mathrm{~T}_{\mathrm{f}}$ \\
\hline & \multirow{2}{*}{$\begin{array}{c}\text { Day } \\
0\end{array}$} & \multirow{2}{*}{ Day 0} & \multirow{2}{*}{ Day 6} & Day 10 & \multirow{2}{*}{$\begin{array}{c}\text { Day } \\
10\end{array}$} & \multirow{2}{*}{$\begin{array}{c}\text { Day } \\
17\end{array}$} & \multirow{2}{*}{$\begin{array}{c}\text { Day } \\
24\end{array}$} & \multirow{2}{*}{$\begin{array}{c}\text { Day } \\
31\end{array}$} \\
\hline & & & & $\left(\right.$ post $\left.\mathrm{T}_{1}\right)$ & & & & \\
\hline \multicolumn{9}{|l|}{ Saturated FA (SFA) } \\
\hline C12:0n & 0.1 & 1 & 1 & $\operatorname{tr}$ & 1 & 1 & 1 & 1 \\
\hline C14:0i & 0.7 & 1 & 1 & $\operatorname{tr}$ & 1 & 1 & 1 & $\operatorname{tr}$ \\
\hline C14:0n & 6.5 & 5.7 & 5.7 & 9.2 & 4.4 & 5.2 & 5.7 & 5.3 \\
\hline C15:0i & 0.5 & tr & tr & 0.5 & tr & tr & tr & tr \\
\hline C15:0a & 0.3 & $\operatorname{tr}$ & $\operatorname{tr}$ & 0.3 & 1 & $\operatorname{tr}$ & $\operatorname{tr}$ & $\operatorname{tr}$ \\
\hline C15:0n & 0.5 & 0.2 & 0.2 & 0.7 & 0.2 & 0.2 & 0.2 & 0.3 \\
\hline C16:0i & 0.3 & tr & $\operatorname{tr}$ & 0.3 & $\operatorname{tr}$ & tr & tr & tr \\
\hline C16:0n & 13.3 & 23.4 & 21.8 & 18.4 & 21.4 & 22.7 & 24.3 & 25.1 \\
\hline C17:0i & 0.1 & tr & tr & 0.2 & tr & tr & tr & tr \\
\hline C17:0a & tr & tr & tr & tr & tr & tr & tr & tr \\
\hline C17:0n & 0.3 & tr & $\operatorname{tr}$ & 0.1 & $\operatorname{tr}$ & tr & tr & tr \\
\hline C18:0i & 1 & 1 & 1 & 1 & 1 & $\operatorname{tr}$ & 1 & $\operatorname{tr}$ \\
\hline C18:0n & 4.8 & 1.7 & 1.4 & 1.4 & 1.7 & 1.5 & 1.7 & 2 \\
\hline C20:0 (methylphytanate) & 0.2 & 1 & 1 & $\operatorname{tr}$ & 1 & 1 & 1 & 1 \\
\hline C20:0n & 0.2 & tr & tr & 0.1 & tr & tr & tr & tr \\
\hline $\mathrm{C} 22: 0 \mathrm{n}$ & 0.3 & 1 & 1 & $\operatorname{tr}$ & 1 & 1 & 1 & 1 \\
\hline $\mathrm{C} 24: 0 \mathrm{n}$ & $\operatorname{tr}$ & 1 & 1 & $\operatorname{tr}$ & 1 & 1 & $\operatorname{tr}$ & $\operatorname{tr}$ \\
\hline \multicolumn{9}{|l|}{ Monounaturated FA (MUFA) } \\
\hline C14:1* & 0.1 & $\operatorname{tr}$ & tr & 0.2 & $\operatorname{tr}$ & tr & tr & tr \\
\hline C15:1* & 0.5 & tr & tr & 0.8 & tr & tr & tr & tr \\
\hline C16:1 (n-7) & 12.0 & 21.3 & 23 & 33.3 & 20.7 & 18.7 & 19.4 & 12.6 \\
\hline C16:1* & 1.5 & 0.4 & 0.4 & 1.5 & 0.4 & 0.4 & 0.4 & 0.4 \\
\hline C17:1* & 0.2 & 0.1 & 0.1 & 0.4 & 0.1 & 0.2 & 0.2 & 0.2 \\
\hline C18:1 (n-9) & 3.1 & 8.7 & 7.7 & 3.4 & 7.5 & 9.5 & 9 & 11.4 \\
\hline C18:1 (n-7) & 3.1 & 9 & 8.4 & 2.6 & 9.8 & 9.4 & 9 & 8.4 \\
\hline C18:1* & 1 & 0.2 & 0.2 & 1 & 0.3 & 0.3 & 0.2 & 0.2 \\
\hline C19:1* & 0.1 & tr & tr & 0.1 & $\operatorname{tr}$ & $\operatorname{tr}$ & tr & $\operatorname{tr}$ \\
\hline C20:1 (n-5) & 1.5 & tr & tr & 0.2 & 0.1 & 0.5 & tr & 0.9 \\
\hline C20:1* & 0.9 & 0.8 & 0.8 & 0.6 & 0.8 & 0.5 & 1 & 0.6 \\
\hline C22:1* & 1.3 & 0.2 & 0.2 & 0.4 & 1 & 0.5 & 0.1 & 0.4 \\
\hline C24:1 (n-9) & 0.2 & 1 & 1 & $\operatorname{tr}$ & 1 & 1 & 1 & $\operatorname{tr}$ \\
\hline $\mathrm{C} 24: 1^{*}$ & 1 & $\operatorname{tr}$ & $\operatorname{tr}$ & 1 & 0.1 & 0.2 & 0.1 & 0.2 \\
\hline \multicolumn{9}{|l|}{ Polyunsaturated FA (PUFA) } \\
\hline C16:2* & 0.7 & 1.3 & 1.4 & 1.3 & 1.5 & 1.5 & 1.4 & 1.4 \\
\hline $\mathrm{C} 16: 3(\mathrm{n}-1)$ & 0.5 & $\operatorname{tr}$ & $\operatorname{tr}$ & 0.9 & 1 & $\operatorname{tr}$ & $\operatorname{tr}$ & $\operatorname{tr}$ \\
\hline $\mathrm{C} 16: 3$ & 0.1 & 1 & 1 & $\operatorname{tr}$ & 1 & 1 & 1 & 1 \\
\hline C16:4 (n-3) & 0.7 & 0.2 & 0.2 & 1.2 & 0.1 & 0.2 & 0.2 & $\mathbf{0 . 3}$ \\
\hline $\mathrm{C} 17: 2$ & 0.2 & $\operatorname{tr}$ & $\operatorname{tr}$ & $\operatorname{tr}$ & 1 & $\operatorname{tr}$ & $\operatorname{tr}$ & $\operatorname{tr}$ \\
\hline
\end{tabular}




\begin{tabular}{|c|c|c|c|c|c|c|c|c|}
\hline C18:2 (n-6) & 2.0 & 0.4 & 0.4 & 1.2 & 0.5 & 0.5 & 0.4 & 0.5 \\
\hline C18:2* & 0.7 & 0.4 & 0.7 & 0.4 & 0.7 & 0.4 & 0.6 & 0.4 \\
\hline C18:3 (n-6) & 4.3 & 0.1 & 0.1 & 0.5 & 0.1 & $\operatorname{tr}$ & 0.1 & $\operatorname{tr}$ \\
\hline C18:3 & 2.2 & 1 & 1 & 2.6 & 1 & 1 & 1 & 1 \\
\hline C18:4 (n-3) & 5.8 & 0.5 & 0.4 & 1.9 & 0.3 & 0.4 & 0.4 & 0.6 \\
\hline C18:4 (n-6) & 1 & $\operatorname{tr}$ & $\operatorname{tr}$ & 1 & $\operatorname{tr}$ & $\operatorname{tr}$ & $\operatorname{tr}$ & $\operatorname{tr}$ \\
\hline $\mathrm{C} 19: 2$ & 1 & $\operatorname{tr}$ & $\operatorname{tr}$ & 1 & $\operatorname{tr}$ & $\operatorname{tr}$ & $\operatorname{tr}$ & $\operatorname{tr}$ \\
\hline $\mathrm{C} 20: 2(\mathrm{n}-6)$ & 0.3 & 1 & 1 & $\operatorname{tr}$ & 1 & 1 & 1 & 1 \\
\hline $\mathrm{C} 20: 2^{*}$ & 1 & 0.2 & 0.2 & 1 & 0.3 & 0.3 & 0.2 & 0.1 \\
\hline C20:3 (n-6) & 0.4 & $\operatorname{tr}$ & 0.16 & 0.2 & 0.1 & 0.1 & 0.1 & 0.1 \\
\hline C20:4 (n-3) & 0.6 & 0.2 & 0.3 & 0.5 & 0.2 & 0.2 & 0.2 & 0.2 \\
\hline C20:4 (n-6) & 1.1 & 0.3 & 0.4 & 0.1 & 0.6 & 0.5 & 0.5 & 0.5 \\
\hline C20:5 (n-3) & 14.3 & 17.7 & 18.2 & 10.4 & 19.5 & 17.4 & 17.4 & 18 \\
\hline $\mathrm{C} 20: 5$ & 1 & 1 & 1 & 1 & 1 & 0.2 & 1 & 0.2 \\
\hline $\mathrm{C} 21: 4$ & 1 & $\operatorname{tr}$ & $\operatorname{tr}$ & 1 & $\operatorname{tr}$ & $\operatorname{tr}$ & $\operatorname{tr}$ & 0.3 \\
\hline C21:5 & 0.2 & 0.3 & 0.3 & 0.1 & 0.3 & 0.3 & 0.3 & tr \\
\hline $\mathrm{C} 22: 5^{*}$ & 1 & 0.4 & 0.4 & 1 & 0.4 & 0.4 & 0.3 & 0.5 \\
\hline C22:6 (n-3) & 12.8 & 5.5 & 6.1 & 3.0 & 7.6 & 7.2 & 5.8 & 7.6 \\
\hline C22:6 & 1 & $\operatorname{tr}$ & $\operatorname{tr}$ & 1 & $\operatorname{tr}$ & $\operatorname{tr}$ & $\operatorname{tr}$ & 0.3 \\
\hline SFA & 28.5 & 31.3 & 29.4 & 32.1 & 27.9 & 29.9 & 32.2 & 33.0 \\
\hline MUFA & 24.7 & 41.0 & 41.0 & 43.4 & 39.9 & 40.2 & 39.7 & 35.6 \\
\hline PUFA & 46.8 & 27.7 & 29.6 & 24.5 & 32.2 & 29.9 & 28.1 & 31.4 \\
\hline Krill FA Conc (mg FA/g WW) & & 23.6 & 21.3 & & 14.1 & 23.3 & 21.6 & 20.9 \\
\hline Particle FA Conc (mg FA/g OC) & 39.6 & & & 89.2 & & & & \\
\hline
\end{tabular}

Pleuthner et al., Appendix 2 


\begin{tabular}{|c|c|c|c|c|c|c|c|c|}
\hline \multirow{2}{*}{$\begin{array}{c}\text { Fatty Acids } \\
\text { (Early Summer) }\end{array}$} & ESu-I & $\begin{array}{c}\text { ESu- } \\
\mathrm{T}_{0} \\
\end{array}$ & $\begin{array}{c}\text { ESu- } \\
\mathrm{T}_{1} \\
\end{array}$ & ESu-P & $\begin{array}{c}\text { ESu- } \\
\mathrm{T}_{2} \\
\end{array}$ & $\begin{array}{c}\text { ESu- } \\
\mathrm{T}_{3} \\
\end{array}$ & $\begin{array}{c}\text { ESu- } \\
\mathrm{T}_{4} \\
\end{array}$ & $\begin{array}{c}\text { ESu- } \\
\mathrm{T}_{\mathrm{f}} \\
\end{array}$ \\
\hline & $\begin{array}{c}\text { Day } \\
0\end{array}$ & Day 0 & Day 5 & $\begin{array}{c}\text { Day } 5 \\
\left(\text { post } T_{1}\right)\end{array}$ & Day 9 & $\begin{array}{c}\text { Day } \\
12\end{array}$ & $\begin{array}{l}\text { Day } \\
16\end{array}$ & $\begin{array}{c}\text { Day } \\
19\end{array}$ \\
\hline \multicolumn{9}{|l|}{ Saturated FA (SFA) } \\
\hline C12:0n & tr & tr & $\operatorname{tr}$ & 0.1 & tr & $\operatorname{tr}$ & 0.1 & tr \\
\hline C13:0n & $\operatorname{tr}$ & $\operatorname{tr}$ & $\operatorname{tr}$ & 0.4 & 1 & $\operatorname{tr}$ & $\operatorname{tr}$ & $\operatorname{tr}$ \\
\hline C14:0i & 0.1 & tr & $\operatorname{tr}$ & 0.3 & tr & $\operatorname{tr}$ & tr & tr \\
\hline C14:0n & 10.1 & 6.6 & 6.5 & 14.7 & 6.2 & 6.0 & 6.4 & 6.3 \\
\hline C15:0i & 0.2 & tr & $\operatorname{tr}$ & 0.4 & tr & $\operatorname{tr}$ & tr & tr \\
\hline C15:0a & 0.2 & tr & tr & 0.3 & tr & tr & tr & tr \\
\hline C15:0n & 0.5 & 0.3 & 0.3 & 0.8 & 0.2 & 0.3 & 0.3 & 0.3 \\
\hline $\mathrm{C} 16: 0 \mathrm{i}$ & 0.4 & $\operatorname{tr}$ & $\operatorname{tr}$ & 0.3 & $\operatorname{tr}$ & 1 & $\operatorname{tr}$ & $\operatorname{tr}$ \\
\hline C16:0n & 15.2 & 27.7 & 27.3 & 21.1 & 29.3 & 29.1 & 26.9 & 27.1 \\
\hline C17:0i & tr & tr & tr & 0.2 & tr & tr & tr & tr \\
\hline C17:0a & tr & tr & tr & tr & tr & tr & tr & tr \\
\hline C17:0n & tr & tr & $\operatorname{tr}$ & 0.2 & $\operatorname{tr}$ & $\operatorname{tr}$ & tr & tr \\
\hline C18:0i & 1 & $\operatorname{tr}$ & 0.1 & 1 & 0.1 & 0.1 & 0.1 & 0.1 \\
\hline C18:0n & 1.1 & 1.9 & 1.9 & 3.1 & 2 & 2.1 & 2.3 & 2.2 \\
\hline C20:0 (methylphytanate) & tr & tr & $\operatorname{tr}$ & tr & tr & $\operatorname{tr}$ & tr & tr \\
\hline $\mathrm{C} 20: 0 \mathrm{n}$ & 0.1 & $\operatorname{tr}$ & $\operatorname{tr}$ & 1 & $\operatorname{tr}$ & $\operatorname{tr}$ & 0.1 & $\operatorname{tr}$ \\
\hline C22:0n & tr & tr & 0.2 & 0.1 & tr & tr & tr & tr \\
\hline $\mathrm{C} 23: 0 \mathrm{n}$ & $\operatorname{tr}$ & $\operatorname{tr}$ & $\operatorname{tr}$ & $\operatorname{tr}$ & 1 & $\operatorname{tr}$ & $\operatorname{tr}$ & $\operatorname{tr}$ \\
\hline C24:0n & tr & tr & $\operatorname{tr}$ & tr & tr & tr & tr & tr \\
\hline \multicolumn{9}{|l|}{ Monounsaturated FA (MUFA) } \\
\hline C14:1* & 0.2 & 0.1 & 0.1 & 0.2 & 0.1 & 0.1 & 0.1 & 0.1 \\
\hline C15:1* & 0.4 & tr & $\operatorname{tr}$ & 0.9 & $\operatorname{tr}$ & $\operatorname{tr}$ & tr & $\operatorname{tr}$ \\
\hline C16:1 (n-7) & 41.7 & 15.6 & 14.9 & 35.6 & 13.8 & 13.4 & 13.6 & 12.7 \\
\hline C16:1* & 2.4 & 0.6 & 0.7 & 2.4 & 0.7 & 0.7 & 0.7 & 0.7 \\
\hline C17:1* & 0.1 & 0.1 & 0.2 & 0.3 & tr & 0.1 & 0.2 & 0.2 \\
\hline C18:1 (n-9) & 1.4 & 11.2 & 10.9 & 1.4 & 12 & 13 & 11.5 & 11.6 \\
\hline C18:1 (n-7) & 2.2 & 8.6 & 8.4 & 3.3 & 9.3 & 9.3 & 9 & 9.6 \\
\hline C18:1* & 1 & 0.3 & 0.3 & 1 & 0.4 & 0.4 & 0.3 & 0.4 \\
\hline C19:1* & tr & tr & tr & 0.1 & tr & tr & tr & tr \\
\hline C20:1 (n-5) & 0.2 & $\operatorname{tr}$ & $\operatorname{tr}$ & 0.2 & $\operatorname{tr}$ & 0.1 & $\operatorname{tr}$ & 0.1 \\
\hline C20:1* & 0.5 & 1.1 & 1.4 & 0.5 & 1.2 & 1.2 & 1.3 & 1.5 \\
\hline C22:1* & 0.2 & 0.6 & tr & 0.6 & 0.5 & 0.6 & 0.7 & 0.8 \\
\hline $\mathrm{C} 23: 1^{*}$ & 1 & $\operatorname{tr}$ & $\operatorname{tr}$ & 1 & $\operatorname{tr}$ & $\operatorname{tr}$ & $\operatorname{tr}$ & $\operatorname{tr}$ \\
\hline C24:1 (n-9) & $\operatorname{tr}$ & 0.2 & 0.2 & $\operatorname{tr}$ & 0.1 & 0.2 & 0.2 & 0.2 \\
\hline $\mathrm{C} 24: 1^{*}$ & 1 & $\operatorname{tr}$ & $\operatorname{tr}$ & 1 & 0.1 & $\operatorname{tr}$ & 0.1 & $\operatorname{tr}$ \\
\hline \multicolumn{9}{|l|}{ Polyunsaturated FA (PUFA) } \\
\hline C16:2* & 1.4 & 1.9 & 2.2 & 2.7 & 2.2 & 2.4 & 2.3 & 2.3 \\
\hline
\end{tabular}




\begin{tabular}{|c|c|c|c|c|c|c|c|c|}
\hline C16:3 (n-1) & 1.1 & $\operatorname{tr}$ & $\operatorname{tr}$ & 0.4 & $\operatorname{tr}$ & $\operatorname{tr}$ & $\operatorname{tr}$ & $\operatorname{tr}$ \\
\hline C16:3 & $\operatorname{tr}$ & $\operatorname{tr}$ & $\operatorname{tr}$ & $\operatorname{tr}$ & 1 & $\operatorname{tr}$ & $\operatorname{tr}$ & $\operatorname{tr}$ \\
\hline C16:4 (n-3) & 2.5 & 0.2 & 0.3 & 0.7 & 0.1 & 0.1 & 0.2 & 0.2 \\
\hline C17:2* & 0.1 & tr & tr & $\operatorname{tr}$ & $\operatorname{tr}$ & $\operatorname{tr}$ & tr & tr \\
\hline $\mathrm{C} 17: 3$ & 1 & $\operatorname{tr}$ & $\operatorname{tr}$ & 1 & $\operatorname{tr}$ & $\operatorname{tr}$ & $\operatorname{tr}$ & tr \\
\hline C18:2 (n-6) & 0.7 & 0.8 & 0.8 & 1.5 & 0.7 & 0.7 & 0.9 & 1 \\
\hline C18:2* & 0.2 & 0.3 & 0.5 & 0.3 & 0.5 & 0.5 & 0.4 & 0.4 \\
\hline C18:3 (n-6) & 0.5 & 0.1 & 0.1 & 0.3 & 0.1 & 0.1 & 0.1 & 0.1 \\
\hline C18:3 & 0.7 & tr & $\operatorname{tr}$ & 0.8 & $\operatorname{tr}$ & tr & tr & tr \\
\hline C18:4 (n-3) & 1.9 & 0.7 & 0.7 & 0.9 & 0.6 & 0.5 & 0.6 & 0.6 \\
\hline C18:4 (n-6) & 1 & $\operatorname{tr}$ & $\operatorname{tr}$ & 1 & $\operatorname{tr}$ & $\operatorname{tr}$ & $\operatorname{tr}$ & $\operatorname{tr}$ \\
\hline $\mathrm{C} 19: 2$ & 1 & $\operatorname{tr}$ & $\operatorname{tr}$ & 1 & 1 & 1 & 1 & 1 \\
\hline C20:2 (n-6) & 0.1 & 1 & 1 & 0.1 & 1 & 1 & 1 & 1 \\
\hline $\mathrm{C} 20: 2^{*}$ & 1 & 0.3 & 0.3 & 1 & 0.3 & 0.3 & 0.3 & 0.3 \\
\hline $\mathrm{C} 20: 3(\mathrm{n}-6)$ & 0.2 & 0.3 & 0.3 & $\operatorname{tr}$ & 1 & 1 & 1 & 1 \\
\hline C20:4 (n-3) & 0.4 & 0.4 & 0.3 & 1 & 0.3 & 0.3 & 0.4 & 0.4 \\
\hline C20:4 (n-6) & 0.2 & 0.2 & 0.2 & 3.3 & 0.2 & 0.2 & 0.2 & 0.2 \\
\hline $\mathrm{C} 20: 4$ & 1 & $\operatorname{tr}$ & $\operatorname{tr}$ & 1 & $\operatorname{tr}$ & $\operatorname{tr}$ & $\operatorname{tr}$ & $\operatorname{tr}$ \\
\hline C20:5 (n-3) & 9.6 & 15.9 & 16.5 & 0.2 & 14.9 & 14.6 & 16.7 & 16 \\
\hline $\mathrm{C} 20: 5$ & 1 & $\operatorname{tr}$ & $\operatorname{tr}$ & 1 & $\operatorname{tr}$ & $\operatorname{tr}$ & $\operatorname{tr}$ & $\operatorname{tr}$ \\
\hline C21:4 & 1 & $\operatorname{tr}$ & $\operatorname{tr}$ & 1 & tr & $\operatorname{tr}$ & $\operatorname{tr}$ & $\operatorname{tr}$ \\
\hline $\mathrm{C} 21: 5$ & $\operatorname{tr}$ & 0.1 & 0.2 & 1 & 0.1 & 0.1 & 0.1 & 0.2 \\
\hline $\mathrm{C} 22: 2^{*}$ & 1 & 1 & 0.3 & 1 & $\operatorname{tr}$ & $\operatorname{tr}$ & $\operatorname{tr}$ & $\operatorname{tr}$ \\
\hline $\mathrm{C} 22: 3$ & 1 & $\operatorname{tr}$ & $\operatorname{tr}$ & 1 & 0.1 & $\operatorname{tr}$ & $\operatorname{tr}$ & $\operatorname{tr}$ \\
\hline $\mathrm{C} 22: 5^{*}$ & 1 & 0.4 & 0.4 & 1 & 0.5 & 0.4 & 0.5 & 0.4 \\
\hline C22:6 (n-3) & 2.4 & 2.3 & 2.5 & 0.4 & 2.2 & 2 & 2.2 & 2.7 \\
\hline C22:6 & 1 & $\operatorname{tr}$ & $\operatorname{tr}$ & 1 & $\operatorname{tr}$ & $\operatorname{tr}$ & $\operatorname{tr}$ & $\operatorname{tr}$ \\
\hline $\mathrm{C} 28: 8$ & $\operatorname{tr}$ & $\operatorname{tr}$ & $\operatorname{tr}$ & 1 & 1 & $\operatorname{tr}$ & $\operatorname{tr}$ & $\operatorname{tr}$ \\
\hline SFA & 28.5 & 37.2 & 36.8 & 42.4 & 38.4 & 38.1 & 36.8 & 36.7 \\
\hline MUFA & 49.4 & 38.6 & 37.3 & 45.7 & 38.5 & 39.4 & 37.9 & 38.2 \\
\hline PUFA & 22.1 & 24.2 & 25.9 & 11.8 & 23.1 & 22.5 & 25.3 & 25.1 \\
\hline Krill FA Cone (mg FA/g WW) & & 80.6 & 68.5 & & 54 & 78.9 & 70.1 & 57.2 \\
\hline Particle FA Conc (mg FA/g OC) & 202.2 & & & 84.8 & & & & \\
\hline
\end{tabular}

Pleuthner et al., Appendix 3 


\section{Table 1}

Summary information for the four sites used for animal and particles incubation experiments. $\mathrm{Chl}$ refers to surface chlorophyll. POC and PN numbers correspond to measurements taken at the particle collection depths.

\section{Table 2}

Algal taxa abundance and estimated biomass for the four sites at which qualitative and quantitative data were available. (Only qualitative FlowCAM data was available from station LSP-I.) *Ciliates include mixotrophs.

\section{Table 3}

Relative abundances of neutral lipids for both particle and T. raschii samples throughout both the late spring (LSp) and early summer (ESu) experiments. Total neutral concentrations for all samples are listed. " " indicates below detection limits; $\operatorname{tr}=$ Trace (Abundance $<0.1 \%$ of neutral lipids); *Particle samples only contained $\alpha$-tocopherol.

\section{Table 4}

The relative abundances of sterols in water column particles (shaded columns) and each krill sub-sample during the late spring (LSp) experiment. Bolded sterols are observed in both krill and water column particles. " " indicates absent or below detection limits; $\mathrm{tr}=$ Trace (Abundance $<0.1 \%) ;{ }^{1}$ sterols coelute; ${ }^{2}$ isomers coelute, but the unknown only in particle samples; ${ }^{*}$ sterols that accounted for $<0.5 \%$ relative abundance in krill and particles (cholest-7-en-3 $\beta$-ol; cholest5,7-dien-3 $\beta$-ol; and 24-methylcholest-7-en-3 $\alpha$-ol) were omitted for brevity.

\section{Table 5}

The relative abundances of sterols in water column particles (shaded columns) and each krill sub-sample during the early summer $(\mathrm{ESu})$ experiment. Bolded sterols are observed in both krill and water column particles. " " indicates absent or below detection limits; $\mathrm{tr}=$ Trace (Abundance $<0.1 \%) ;{ }^{1}$ sterols coelute; ${ }^{2}$ isomers coelute, but the unknown only in particle samples; ${ }^{*}$ sterols that accounted for $<0.5 \%$ relative abundance in krill and particles (cholest-7-en-3 $\beta$-ol; cholest-

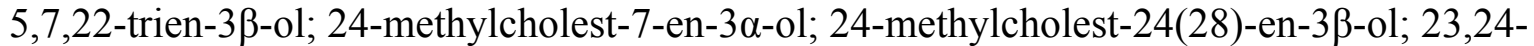
dimethylcholest-5,22-dien-3 $\beta$-ol; 24-ethylcholest-7-en-3 $\beta$-ol; and 24-propylcholest-5,24-dien$3 \beta$-ol,) were omitted for brevity.

\section{Appendix 1}

Physiological information regarding the T. raschii krill composites for the late spring and early summer experiments.

\section{Appendix 2}

Total fatty acid concentration and percent composition of individual fatty acids in particle samples (shaded columns) and all krill sub-samples taken throughout the late spring experiment. Fatty acids seen in both the water column and krill samples are in bold. $\backslash=$ absent or below detection limits; $\operatorname{tr}=$ Trace $($ Relative abundance $<0.1 \%$ ); *inclusion of multiple isomers. Fatty acids present in trace abundance in particles only were excluded for brevity and include C12:0n, C13:0i, C13:0a, C13:0n, C14:0a, C23:0n, and C26:0n. 
Appendix 3

Total fatty acid concentration and percent composition of individual fatty acids in particle samples (shaded columns) and all krill sub-samples taken throughout the early summer experiment. Fatty acids seen in both the water column and krill samples are in bold. $\backslash=$ absent or below detection limits; $\operatorname{tr}=$ Trace (Relative abundance $<0.1 \%$ ); *inclusion of multiple isomers.

Fatty acids present in trace abundance in particles only were excluded for brevity and include C12:0n, C13:0i, C14:0a, C26:0n, and C26:1. 